\title{
AIAA 2001 - 0562 \\ Measured and Computed Hypersonic Aerodynamic/Aeroheating Characteristics for an Elliptically Blunted Flared Cylinder
}

Francis A. Greene, Gregory M. Buck, and William A. Wood NASA Langley Research Center Hampton, Virginia 23681

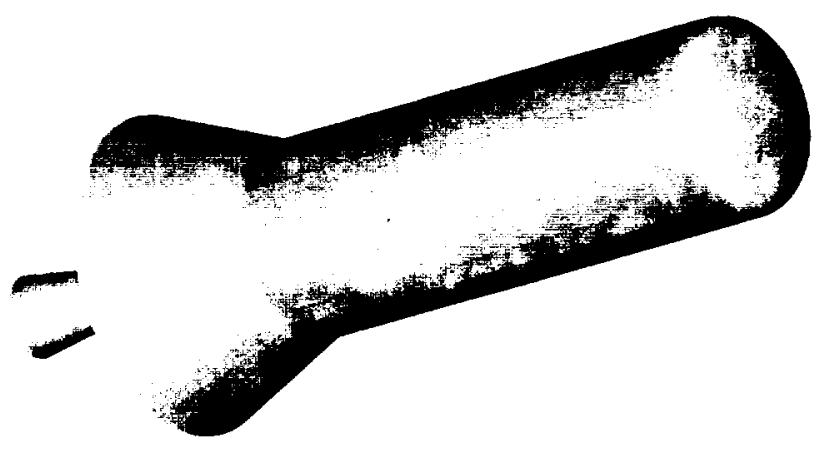

$39^{\text {th }}$ Aerospace Sciences Meeting \& Exhibit January 8-11, 2001 Reno, Nevada 

, 


\title{
Measured and Computed Hypersonic Aerodynamic/Aeroheating Characteristics for an Elliptically Blunted Flared Cylinder
}

\author{
Francis A. Greene ${ }^{*}$, Gregory M. Buck ${ }^{\dagger}$, and William A. Wood ${ }^{\dagger}$ \\ NASA Langley Research Center, Hampton, VA 23681
}

\begin{abstract}
Computational and experimental hypersonic aerodynamic forces and moments and aeroheating levels for Kistler Aerospace Corporation's baseline orbiter vehicle at incidence are presented. Experimental data were measured in ground-based facilities at the Langley Research Center and predictions were performed using the Langley Aerothermodynamic Upwind Relaxation Algorithm code. The test parameters were incidence (-4 to 24 degrees), freestream Mach number (6 to 10$)$, freestream ratio of specific heats (1.2 to 1.4), and freestream Reynolds number $(0.5$ to 8.0 million per foot). The effects of these parameters on aerodynamic characteristics, as well as the effects of Reynolds number on measured heating levels are discussed. Good agreement between computational and experimental aerodynamic and aeroheating values were observed over the wide range of test parameters examined. Revnolds number and ratio of specific heats were observed to significantly alter the trim L/D value. At Mach 6. laminar flow was observed along the entire windward centerline up to the flare for all angles and Reynolds numbers tested. Flow over the flare transitioned from laminar to transitionaliturbulent berween 4 and 8 million per foot at 8 and 12 degrees angle of attack, and near 4 million per foot at 16 degrees angle of attack.
\end{abstract}

\begin{tabular}{|c|c|}
\hline & Nomenclature \\
\hline $\mathrm{C}_{\mathrm{A}}$ & $\begin{array}{l}\text { total axial force coefficient (includes base } \\
\text { pressure) }\end{array}$ \\
\hline$C_{m}$ & pitching-moment coefficient \\
\hline & $\begin{array}{l}\text { longitudinal stability parameter, per radian } \\
\text { normal force coefficient }\end{array}$ \\
\hline$C_{P}$ & pressure coefficient \\
\hline $\mathrm{L} / \mathrm{D}$ & lift-to-drag ratio \\
\hline Q & non-dimensional heat rate \\
\hline $\mathrm{Re}$ & Reynolds number, per foot \\
\hline$\alpha$ & angle of attack, degree \\
\hline$\phi$ & radial angle, degree $(0=$ leeside, $180=$ windside $)$ \\
\hline$\gamma$ & ratio of specific heats \\
\hline$\rho$ & density, slug/ $/ \mathrm{ft}^{3}$ \\
\hline Subs & \\
\hline$\infty$ & freestream values \\
\hline & post-shock values \\
\hline
\end{tabular}

\section{Introduction}

To significantly lower Earth to orbit (ETO) costs, aircraft like operations are being incorporated into the designs of fully reusable space transportation system concepts. Several entrepreneurial start-up companies are stepping in to fill the low-cost launch void by building reusable launch vehicles (RLV) to service the low and medium Earth orbit launch markets ${ }^{1}$. Their intention is to capitalize on the growth in the commercial space sector ${ }^{2}$ in traditional and new industries. The RLV under development by Kistler Aerospace Corporation is a fully reusable two-stage-to- orbit (TSTO) space transportation system. By rolling the lift vector, each stage is steered to a landing point that is near the launch site ${ }^{3}$. The first-stage, referred to as the launch assist platform (LAP), returns shortly after launch. The second-stage or orbiter vehicle (OV) returns to the launch site after the payload has been deployed and is the focal point of this paper.

Because the trim angle of the OV is determined based on the balance of aerodynamic forces acting on the vehicle unaided by reactive jets or movable control surfaces, an accurate description of the aerodynamic environment is crucial if the vehicle is to land within a prescribed area surrounding the launch site. Similarly, for a successful flight, an accurate description of the aeroheating environment is crucial for the proper selection, sizing, and split-line locations of the thermal protection system (TPS) material. Inaccuracy in the aeroheating data used in the design of the TPS or in the aerodynamic data used in the guidance and control algorithms could result in vehicle failure or limit vehicle capabilities in its operational mode. To avoid inaccuracy, factors that influence flight aerodynamic or aerothermodynamic values should be identified and accounted for.

The influence of reacting gas chemistry within the shock layer has a significant impact on aerodynamic and aeroheating values and is quantified best using computational methods. Before a computational fluid dynamics (CFD) tool is employed to numerically predict data used in the design of flight vehicle, the credibility of the CFD tool should be established. While this is a multi-step process, generally, a first step

* Aerospace Technologist. Aerothermodynamics Branch. Aerodynamics. Aerothermodynamics and Acoustics Competency. Senior Member ALAA

'Aerospace Technologist. Aerothermodynamics Branch. Aerodynamics. Aerothermodynamics and Acoustics Competency

Copyright $(2001$ by the American Institute of Aeronautics and Astronautics. Inc. No copyright is asserted in the United States under Title 17. U.S. Code. The U.S. Government has a royalty-free license to exercise all rights under the copyright claimed herein for Governmental Purposes. All other rights are reserved by the copyright owner.

-1 - 
is to ensure the computational tool can reproduce perfect gas wind tunnel data and flow physics when applied to the subject vehicle at incidence. If the CFD tool is not successful at this step, then its credibility for predicting data at flight conditions is in question

Computational and experimental hypersonic aerodynamic forces and moments and aeroheating levels are presented for Kistler Aerospace Corporation's baseline OV configuration at incidence. Continuum laminar CFD predictions for $\mathrm{CF}_{4}$ (tetrafluoromethane) and perfect gas air were obtained using the Langley Aerothermodynamic Upwind Relaxation Algorithm (LAURA) ${ }^{4}$ code. Aerodynamic coefficients and aeroheating levels from LAURA are compared with corresponding measured data obtained at Langley Research Center's (LaRC) Aerothermodynamic Facilities Complex (AFC) ${ }^{5,6}$. Specifically, the experimental data were measured in the AFC 20-Inch Mach $6 \mathrm{CF}_{4}, 20$-Inch Mach $6 \mathrm{Air}$, and 31-Inch Mach 10 Air Tunnels and covered an angle of attack (AOA) range of -4 to 24 degrees, and a Reynolds number range of 0.5 to 8 million per foot. Comparing data from the AFC tunnels allows the influence of vehicle attitude, Mach number, Reynolds number, and ratio of specific heats $(\gamma)$ on aerodynamic and aeroheating values to be assessed. The influence of these parameters on aerodynamic values is discussed. Furthermore, flow visualizations from experiment, compared with corresponding images from CFD predictions, are presented. Finally, the influence of Reynolds number on aeroheating levels is presented. Aerodynamic and aeroheating reference values and the center of gravity location were withheld at Kistler's request.

\section{Computational Model and Grid}

A numerical representation of the baseline $O V$ and the symmetry plane grid is shown in Figure 1 . The numerical predictions were performed on a computational geometry that did include the engine nozzle and wake, but did not include raceways like those shown in Figure 2. The OV is reminiscent of the Polaris re-entry stage: a flare stabilized elliptically blunted cylinder. The inner-mold line of the full-scale baseline OV measures 611 inches in length from nose to flare end; the cylinder radius is 82.3 inches; the maximum flare radius is 132.0 inches, and the flare angle is 21 degrees. The nose radius is 165.3 inches and a 25.5-inch radius curve is used to transition from the nose to the cylinder. A 27.9-inch radius curve fills the cylinder-flare junction.

The predictions were computed on a three-block "medium" grid system. The first block covered the main body ( 89 streamwise $\times 37$ circumferential $\times 65$ points between the body and outer domain); the second covered the nozzle wake $(29 \times 37 \times 85)$, and the third covered the trailing wake $(21 \times 37 \times 101)$. For each solution, the outer grid domain was adapted to conform to the bow shock. Also, points in the direction normal to the surface were redistributed such that the cell Reynolds number at the wall was of order one and the grid stretching in the boundary layer was less than 1.2. Using this criterion, LAURA has accurately predicted surface heat transfer and aerodynamics at wind tunnel and flight conditions $7,8,9,10$.

\section{Computational Method}

LAURA is a finite-volume shock-capturing pointimplicit structured grid solver that relaxes either the Euler, thin-layer Navier-Stokes, or full Navier-Stokes equations in pseudo time to a steady state. The inviscid first-order flux is upwind biased using Roe's fluxdifference splitting ${ }^{11}$ with Harten's entropy fix ${ }^{12}$ and is extended to second-order with Yee's Symmetric Total Variation Diminishing (STVD) approach ${ }^{13}$. Viscous terms are incorporated via second order central difference approximations. LAURA operates efficiently in a macro-tasked or parallel computing environment and is capable of predicting laminar or turbulent $^{14}$ aerothermodynamics for perfect gas ${ }^{15}$, tetrafluoromethane $\left(\mathrm{CF}_{4}\right)$, equilibrium ${ }^{16}$, or nonequilibrium $^{17}$ flows. The LAURA predictions presented correspond to the wind tunnel conditions listed in Table 1 and were made assuming laminar viscous (thin-layer Navier-Stokes) flow for $\mathrm{CF}_{4}$, and perfect gas air. The wall temperature was constant for all cases; it was set to 540 Rankine.

\section{Experimental Model}

The aerodynamic and aeroheating data were measured on one-percent scale models. Aeroheating data were obtained using the two-color, relative intensity, phosphor thermography technique ${ }^{18}$. The aeroheating data were then reduced and analyzed using the IHEAT $^{18}$ code. The global data produced by this technique permit the resolution of complex flow phenomena such as transition fronts, vortex structures, and shock interactions. To obtain accurate heat transfer measurements with the phosphor thermography technique, models are cast from a silica ceramic material that has a low diffusivity, is well defined, and has uniform thermal properties. These models are coated with a mixture of phosphors suspended in a silica-based colloidal binder. The phosphor models tested, one of which is shown in Figure 2, included the raceways, but did not include a representation of the engine nozzle.

Pictured in Figure 3 are the baseline model, raceways, a cylinder extension, and a flare extension used for force and moment tests. The extensions were used to construct variants of the baseline configuration; 
these variants were tested, but are not the subject of this document. On the flight vehicle, the raceways are located \pm 30 degrees off the leeward symmetry plane. The force and moment data presented were measured on the baseline OV model without raceways or an engine nozzle. In the air and $\mathrm{CF}_{4}$ facilities, a stainless steel nose was mated to an aluminum body. This setup reduced conduction heating effects on the strain-gage balance.

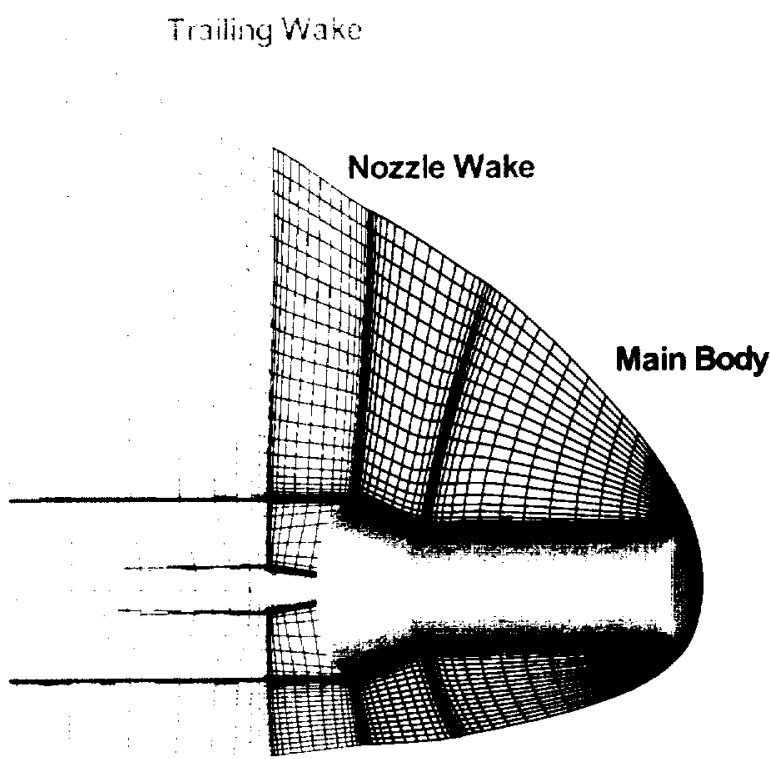

Figure 1. Computational model - baseline OV \& symmetry plane grid.

\section{Experimental Facilities}

The experimental data presented in this document were measured in three hypersonic facilities that are part of the LaRC AFC. Nominal flow conditions for each facility are listed in Table 1 . All three facilities, the 20-Inch Mach $6 \mathrm{CF}_{4}, 20$-Inch Mach $6 \mathrm{Air}$, and 31Inch Mach 10 Air Tunnels are similar in their operation. Each is a blow-down-to-vacuum wind tunnel that uses a filtered test gas. The gas is transferred from a highpressure storage facility to a heater. To prevent liquefaction, the air and $\mathrm{CF}_{4}$ gas are heated. The gas is then regulated to the desired pressure and passed through filters to remove particles ( $>5$-microns) before entering the settling chamber. From the settling chamber, the filtered gas expands through a nozzle and enters the test section at the design Mach number. Once through the test section, the gas is slowed to a subsonic velocity and collected in vacuum spheres. The $\mathrm{CF}_{4}$ tunnel is a closed-circuit tunnel. The gas is recovered from the vacuum spheres, impurities removed, and the gas stored for subsequent use. Details regarding tunnel operating ranges and specifications can be found in Refs. 5 and 6.

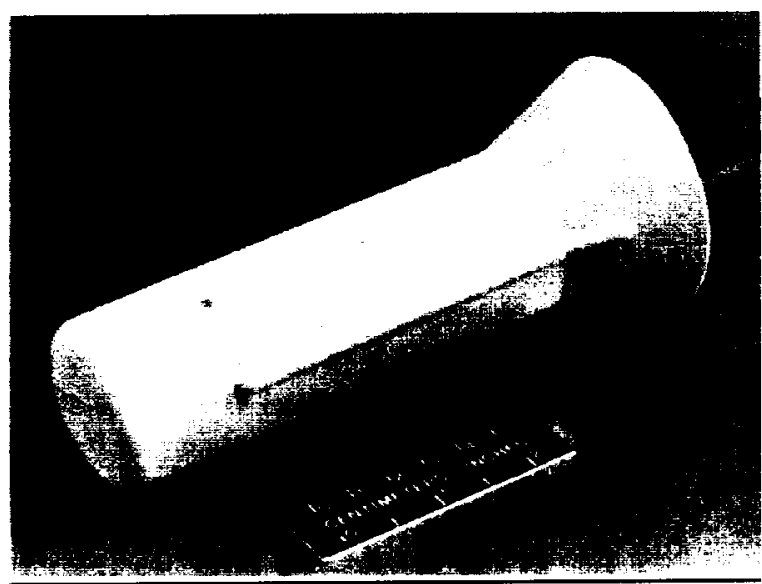

Figure 2. One-percent scale thermographic phosphor model for the K-1 OV.

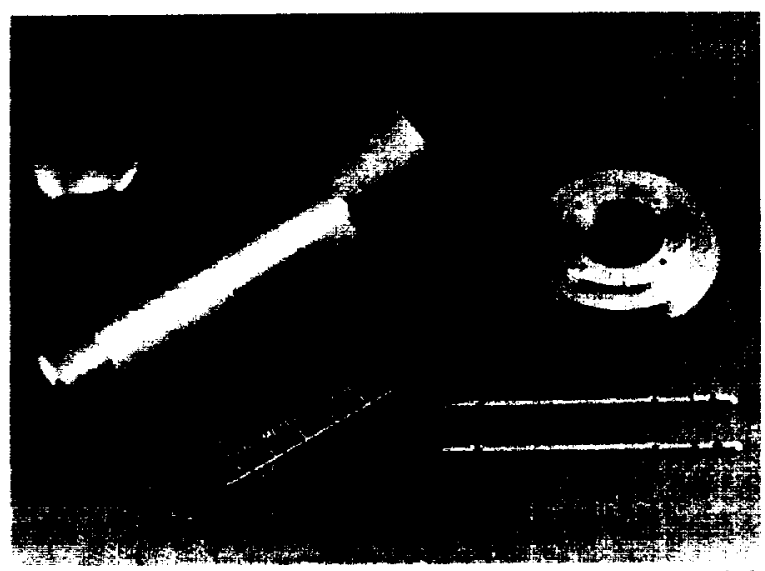

Figure 3. One-percent scale force and moment model for the K-1 OV.

\section{Data Uncertainties}

For aerodynamic data on the baseline OV, repeat runs were made, references for similar configurations were consulted, and the measured (i.e. experimental) data were compared with predictions from CFD. A statistical uncertainty analysis has not been performed to date; however, the error in aerodynamic values expressed as a percentage ( 0.5 percent) of the full-scale balance load is presented in Table 2 . The experimental aerodynamic values were corrected for sting deflections. During aerodynamic testing, the state of the boundary layer on the test model in the facilities is not explicitly known. However, the LAURA predictions at wind tunnel conditions presented in this report were made assuming laminar flow. The appropriateness of the laminar assumption for air is supported by subsequently measured heating trends with Reynolds number. Due to the low operating Reynolds numbers in the $\mathrm{CF}_{4}$ facility, the flow is 
believed to be laminar. To add confidence in the computational solutions, a check for grid convergence was conducted. In comparing aerodynamic coefficients from the mesh used with values from a finer mesh (surface dimensions increased by a factor of two), less than a one percent change was observed in all aerodynamic forces and moments.

As discussed in Ref. 18, the accuracy of the phosphor technique is dependent on the temperature rise on the surface of the test model. For heating measurements on windward surface, the accuracy of the phosphor system is estimated to be approximately \pm 8 percent, and the overall experimental uncertainty of the heating data due to all factors is estimated to be \pm 15 percent. Because the leeside temperature increase is only a few degrees during a test, the experimental uncertainty for leeside aeroheating rates increases to \pm 25 percent. Computed aeroheating levels at three longitudinal distributions for the medium and fine grids are shown in Figure 4. Medium and fine grid aeroheating values compare within three percent, with the exception of the leeward flare region. The overall error for a grid converged LAURA solution is approximately \pm 10 percent.

\section{Results and Discussion}

Aerodynamic and aeroheating data were measured at Langley Research Center's 20-Inch Mach $6 \mathrm{CF}_{4}, 20$ Inch Mach 6 Air, and 31 -Inch Mach 10 Air Tunnels on one-percent scale models of Kistler Aerospace Corporation's baseline orbiter vehicle. The data was obtained over the wide range of incidence, Mach number, Reynolds number, and ratio of specific heats listed in Table 1. In this section, these measured data are compared corresponding computational data from the LAURA code and the effects of attitude, Reynolds number, ratio of specific heats, and Mach number on aerodynamic characteristics are described. Following this, computed and measured aeroheating levels, as well as aeroheating trends with Reynolds number are presented.

\section{Predicted ys. measured aerodynamics}

Displayed in Figures 5-7 are plots of experimental and computational aerodynamic data. Measured values are represented by open symbols and predicted values by a solid line through a filled symbol. The axial force coefficient, normal force coefficient, pitching moment coefficient, and lift-to-drag ratio for air at Mach $6(\mathrm{Re}=$ 4.0 million per foot) are presented in Figure 5. The same quantities for air at Mach $10(\mathrm{Re}=2.0$ million per foot), and for $\mathrm{CF}_{4}$ at Mach 6 ( $\mathrm{Re}=0.4$ million per foot) are presented in Figures 6 and 7, respectively. Because agreement comparable to that in the above figures was observed across the Reynolds number range, to avoid redundancy, comparisons at other Reynolds numbers for air data at Mach 6 and 10 are not included. Also, contributions to the aerodynamics from the engine nozzle were not included in the computed data, since the nozzle was not part of the experimental configuration.

The numerical predictions compare well with the experimental data. For Mach 6 air, differences between measured and computed values are generally within six percent for $C_{A}, L / D$, and $C_{m}$, and within four percent for $\mathrm{C}_{\mathrm{N}}$. Experimental Mach 10 values, shown in Figure 6 , for $C_{A}$ and $C_{N}$ agree with the corresponding $C F D$ values within four percent, while differences of 7-10 percent exist for $C_{m}$ and L/D. Shown in Figure 7 is data at the Mach $6 \mathrm{CF}_{4}$ condition. The percentage agreement is similar to that observed for the Mach 10 data. In general, predicted and measured coefficient values of $C_{N}$ and $C_{A}$ are within four percent, and $C_{m}$ and $L / D$ are within 10 percent. Good agreement between computed and measured aerodynamic coefficients is observed. This good agreement, which exists at incidence with significant three-dimensional effects and over a wide range in flow conditions, demonstrates the ability of the CFD tool to reproduce data at varied wind tunnel conditions and augments the credibility of LAURA to predict aerodynamic data at flight conditions.

\section{Angle of attack effects}

With increased incidence, factors such as flow asymmetry between the windward and leeward surfaces, changes in separation and reattachment points, and the movement of the bow shock relative to the vehicle surface, affect aerodynamics by altering surface pressure distributions. In addition, as the flow is processed through the flare shock, pressure levels on the flare are elevated in a non-linear manner.

The behavior of aerodynamic coefficients with angle of attack is displayed in Figures 5-7. These figures show the qualitative behavior of the coefficients with angle of attack is independent of Mach number, Reynolds number, and ratio of specific heats. At all flow conditions, a change in the slope of the aerodynamic values occurs near 10 degrees. Near this angle, pressure levels on the flare have increased to a point where their influence on the aerodynamic coefficients is noticeable. This influence continues to increase non-linearly with angle of attack and is primarily responsible for the steeper slopes in the aerodynamic data between 10 and 20 degrees. In the Mach 10 air and the Mach $6 \mathrm{CF}_{4}$ data, a second change in slope is present near 20 degrees. This second change is caused by the bow-shock flare-shock interaction and is not observed in the Mach 6 air data because the responsible interaction occurs at an angle that is beyond the displayed angle of attack range. An expansion fan generated by the shock-shock interaction reflects off the 
flare surface, and with increasing angle of attack, results in a decrease in wind side pressure on the aft end of the flare. Previous studies on similar configurations have noted the same phenomenon ${ }^{19}$. Figure 8 is a plot of the computed pressure coefficient along the windward centerline for Mach $6 \mathrm{CF}_{4}$ at 20 and 24 degrees angle of attack. The figure shows the decrease in pressure coefficient over the aft end of the flare as the angle of attack is increased.

The nose, cylinder, and flare components to the aerodynamic coefficients from the LAURA solutions at Mach 6 in air are plotted in Figure 9. At low angles, the contribution from the sum of the nose and cylinder to the aerodynamic coefficients is comparable to or is greater than the value from the flare. With increased angle of attack, the flare contribution to the aerodynamic coefficients grows more rapidly than the contribution associated with the nose and cylinder. With the exception of a very slight non-linearity in $C_{N}$ from the cylinder (when compared with non-linear behavior on flare), nose and cylinder aerodynamic contributions are essentially linear with angle of attack. The CFD data in Figure 9 indicate the non-linear nature in the aerodynamic coefficients with angle of attack is derived from the flare. This non-linear behavior is consistent with similar blunt-nosed flare-stabilized configurations $^{20}$ and is due to the variation of the pressure distribution for the flare.

\section{Reynolds number effects}

The effects due to the variation in Reynolds number on longitudinal aerodynamics are conveyed through plots of $C_{A}, C_{N}, C_{m}$, and $L / D$ as displayed in Figure 10. Measured Mach 6 air data at Reynolds numbers equal to $0.5,1.0,2.0$, and 4.0 million per foot, and Mach 6 inviscid air CFD predictions from the DataParallel Lower-Upper Relaxation (DPLUR) ${ }^{21}$ flow solver are shown. The inviscid data represent the bound in the data with increasing Reynolds number. It should be noted, the DPLUR solution was non-inclusive of the wake; consequently, the experimental axial force coefficient data in this section does not include base pressure contributions. (The base pressure contributes approximately 2 to 4 percent to the total axial force at this condition).

The data presented in Figures 10(b) and 10(d) show the effect of Reynolds number on $C_{N}$, and $L / D$ is, in general, negligible across the angle of attack range considered. However, the data presented in Figures 10 (a) and $10(\mathrm{c})$ indicate Reynolds number induced changes exist in $C_{m}$ and exist as expected in $C_{A}$. At a given angle of attack, the difference between the maximum and minimum experimental axial force coefficient value at Mach 6 in air is approximately 10 percent. The largest portion of this percentage occurs between 0.5 and 1.0 million per foot. Beyond 1.0 million per foot, the experimental values asymptotically approach the inviscid values. The difference between the experimental axial coefficient data at the highest Reynolds number and the inviscid CFD data is two percent or less. This implies that the influence of viscosity on $C_{A}$ is small beyond 4 million per foot. (This conclusion was also reflected in unpublished data at Mach 20 in Helium, which had a larger Re variation compared with the air data at Mach 6. The Reynolds numbers (based on body length) for Helium were equivalent to flight values). At low angles of attack ( $<$ 10 degrees), experimental values of $C_{m}$ have a small dependence with Reynolds number and the difference between the high Reynolds number experimental data and the inviscid data is also small, but observable. In this region, the high Reynolds number data exhibit a larger instability (larger $C_{m}$ values). While the dependence on pitching moment with Reynolds number is small, a change is present in trim angle of attack between the high Reynolds number experimental data and the inviscid data. For Mach 6 air, approximately a two-degree change was observed between the high Reynolds number experimental data and computational inviscid data. This small change in trim angle is significant because it occurs at a location were the L/D value varies rapidly with angle of attack. This change in trim angle translates into an increase in trimmed $L / D$ with Reynolds number at Mach 6 and is indicated on Figure 10(d). Finally, longitudinal stability, measured by $\left(C_{m}\right)_{\alpha}$, while difficult to infer from Figure $10(\mathrm{c})$, is slightly enhanced with increasing Reynolds number.

\section{Mach number effects}

Just as differences in shock layer properties induced by high temperature chemistry can affect the aerodynamic character of a vehicle traveling at hypervelocities, differences in shock layer properties induced by changes in Mach number under perfect gas conditions can also affect aerodynamic character. Shock standoff and shock angle are a function of the conditions across the shock and variations in standoff or angle can alter surface pressure.

In Figure 11, the effects on aerodynamics that result from changes in Mach number are displayed through plots of $C_{A}, C_{N}, C_{m}$, and $L / D$ data measured at Mach 6 and 10 at a Reynolds number of approximately 2.0 million per foot. Initially, values of $\mathrm{C}_{\mathrm{N}}$ and $\mathrm{C}_{\mathrm{A}}$ are generally lower for Mach 10, with the gap closing as 20 degrees is approached. Near of 20 degrees, Mach 10 values exceed those at Mach 6; however, at the largest angle considered, the bow-shock flare-shock interaction reverses the order, causing values of $\mathrm{C}_{\mathrm{N}}$ and $\mathrm{C}_{\mathrm{A}}$ at Mach 6 to exceed their respective values at Mach 10. Lift-todrag trends follow those noted for $C_{K}$ and $C_{A}$, except at the highest angle of attack. The characteristics of the pitching moment curve are also affected. Data in

-5 - 
Figure 11(c) reveal $C_{m}$ increases with Mach number for angles of attack less than 15 degrees. At angles greater than 15, Mach 10 values are more negative. At the highest angles $(\alpha>20)$, the change in the value of Mach 10 pitching moment coefficient is a result of the bow-shock flare-shock interaction influencing flare pressures. The interaction onset angle is lower for Mach 10 due to its smaller bow shock standoff distance. The effect of Mach number on longitudinal stability, $\left(C_{m}\right)_{\alpha}$, is inferred from Figure 11(c). For angles between 0 and 10 degrees, the stability of the baseline $\mathrm{OV}$ is reduced with increasing Mach number. This finding is consistent with data contained in Ref. 22 for similar configurations at 0 incidence. At trim, the vehicle is more stable at Mach 10 than at Mach 6, indicating enhanced longitudinal stability with increasing Mach number. This trend continues to 20 degrees angle of attack. The largest Mach number induced differences in lift-to-drag are found in the region surrounding the trim angle. While the delta in L/D appears significant, a Mach number induced change in trim angle of attack causes the trim $L / D$ value to increase slightly with Mach number.

\section{$\boldsymbol{\gamma e f f e c t s}$}

Under certain conditions, the $\mathrm{CF}_{4}$ Tunnel can provide a simulation of the effect of $\gamma$ and density ratio and thereby provide good estimates of flight aerodynamics ${ }^{23}$. However, in general, it is not assumed that testing with $\mathrm{CF}_{4}$ gas will predict flight aerodynamics. But rather, by comparing Mach 6 air with Mach $6 \mathrm{CF}_{4}$ data, the two facilities provide insight on how the aerodynamic characteristics of a returning space transportation vehicle is influenced by $\gamma$ and density ratio. Using a heavy gas, $\mathrm{CF}_{4}$, as the test medium, post normal-shock values of $\gamma(\approx 1.1)$ and post normal-shock values of density ratio $(\approx 12)$ on the order of those encountered during hyper-velocity flight are created in a ground-based facility. Consequently, shock detachment distance and pressure compression/ expansion behavior similar to that encountered during flight are produced. The lower values of $\gamma$ associated with reacting gas air affect aerodynamics by producing higher compressions and lower expansions in pressure relative to those produced by perfect gas air. Because of this, it is especially critical to quantify this behavior when the vehicle has a compression or expansion surface ${ }^{24}$.

The effect of $\gamma$ on longitudinal aerodynamic values is presented in Figure 12. In the figure, $C_{A}, C_{N}, C_{m}$ and L/D data measured at Mach 6 for a Reynolds number of approximately $0.5 \times 10^{6}$ per foot in air and $\mathrm{CF}_{4}$ are plotted. The data in Figure 12(a) indicate $\gamma$ has a small (3-4 percent) effect on $C_{A}$. For angles up to approximately 8 degrees, $C_{N}, C_{m}$, and $L / D$ show negligible differences due to $\gamma$. Past 8 degrees, the influence of $\gamma$ becomes significant and differences are produced which increase rapidly with angle of attack. Beyond 20 degrees, the change in $C_{m}$ character exhibited in $\mathrm{CF}_{4}$ is a result of the shock-shock interaction. Due to the higher density ratio in $\mathrm{CF}_{4}$, the shock detachment distance is less than that for air; therefore, the influence of the expansion fan on the flare occurs at lower angle of attack. Differences in shock structure are discussed in the next section.

The variation in aerodynamic coefficients between air and $\mathrm{CF}_{4}$ arise from $\gamma$ induced pressure differences. These pressure differences are small on the nose and cylinder and are significant on the flare. Therefore, at low angles, where the nose and cylinder contribute most to the aerodynamics, aerodynamic variations due to $\gamma$ are small. At higher angles, when aerodynamic contributions from the flare become significant, differences in aerodynamic characteristics are prominent.

Consistent with past sources, the data show changes in $\gamma$ can significantly alter the aerodynamic character. An increase in flare effectiveness is observed in $\mathrm{CF}_{4}$ until the bow-shock flare-shock interaction influences pressures on the flare; furthermore, trim angle and trim L/D are affected. The trim angle in flight will be determined by the balance of aerodynamic forces, unaided by moveable control surfaces; consequently, knowing the influence of $\gamma$, or any variable, on the trim angle is critical with respect to $L / D$ and aerothermal issues. Based on the data in Figure 12, not accounting for high temperature chemistry would result in an over prediction in trim angle of attack. Inaccuracy in trim angle would affect the guidance and control algorithms and the split line layout for the TPS. Also shown is a considerable over prediction in L/D at trim, which would affect cross-range estimates.

\section{Flow visualization}

The schlieren images shown in Figure 13 convey the OV bow and flare shock locations in Mach 6 air at a 2 million per foot Reynolds number condition at 0,10 , and 20 degrees angle of attack. The dashed line overlaid on each schlieren image indicates the numerically predicted bow shock location from the LAURA code for Mach 6 air at a freestream condition corresponding to experiment. The dot-dashed line overlaid on each image indicates the numerically predicted bow shock location for Mach $6 \mathrm{CF}_{4}$. Comparing the two lines illustrates the dissimilar shock detachment distance that result from changes in density ratio. The normal-shock density ratio for $\mathrm{CF}_{4}$ is more than twice the value for air. For the same angle of attack, compared with air, the shock detachment distance is smaller for $\mathrm{CF}_{4}$ and more closely simulates a 
shock structure encountered during Earth entry. Evident in Figure 13 is the outline of the OV, the location of the bow and flare shock, and the bow-shock flare-shock intersection at the highest angle of attack. The agreement of prediction with experiment for the flare shock location is excellent. From this agreement it can be concluded that the numerical method is accurately capturing the shock and is reproducing density ratios across the shock in agreement with experiment. The agreement between measured and computed bow shock location for Mach $6 \mathrm{CF}_{4}$ is comparable to that displayed for Mach 6 air and images are not presented to avoid redundancy. Based predicted $\mathrm{CF}_{4}$ shock locations, in flight near trim, it appears the shock-shock interaction will not affect the aerothermodynamic or aerodynamic characteristics of the OV.

\section{Surface heating}

Measured surface heating levels, inferred using phosphor thermography, were obtained at Mach 6 and 10 in air at the conditions listed in Table 1. These measured data, along with predicted laminar values from the LAURA code, are presented in nondimensional form in Figure 14. Primary emphasis is given to the windward surface. Data along the windward centerline at three angles of attack that are in the vicinity of the expected trim angle of attack are shown. Specifically, measured data at 8,12 , and 16 degrees are considered. While there is a 1 to 2 degree difference in angle of attack between measured and computed values, in general, the two techniques exhibit similar trends and have good qualitative agreement. On the cylinder, the computed heating values at Mach 6 are higher than measured values (see Figure 14 (a)); however, good quantitative agreement is well within the stated uncertainty of the measured data. On the flare, the computed data at 10 degrees are bound by the experimental data at 8 and 12 degrees and good agreement is within the uncertainty of the measured data. At 15 degrees, computed data over the first half of the flare is in qualitative agreement with measured data at 16 degrees; like the data at 10 degrees, good agreement is within the uncertainty of the measured data. Over the last half of the flare, heating trends with Reynolds number at 16 degrees that are presented in Figure 15(c) indicate transitional/turbulent. Computed and measured data at Mach 10 agree well with each other along the cylinder and the flare. The agreement of the experimental data with the laminar predictions is indicative of the measured data being laminar on the windward surface. The agreement of measured with computed data is well within the uncertainty limits. Like the Mach 6 data at 10 degrees, the Mach 10 data at 10 degrees are also bound by the experimental data at 8 and 12 degrees.
The effect of Reynolds number at Mach 6 in air on non-dimensional heating along the $\mathrm{OV}$ windward centerline at 8,12 , and 16 degrees is presented in Figure 15. At all angles considered, the aeroheating data along the entire length of the cylinder is independent of Reynolds number, indicating laminar flow. At 8 degrees (see Figure 15(a)), the flow over the flare remains laminar up to 4 million per foot, and appears transitional/turbulent at 8 million per foot. The measured aeroheating data on the flare at 12 degrees (see Figure 15 (b)) varies with Reynolds number, but the trend is not indicative of transitional/turbulent flow since the heating levels do not increase with Reynolds number. However, measured heating levels were near those for laminar CFD predictions. Approximately half way down the flare, the 16-degree aeroheating data at 4 million per foot (see Figure 15(c)) rapidly increase compared with values at lower Reynolds numbers. Phosphor images displayed as a function of Reynolds number are shown in Figure 16. A localized increase in heating is visible on the aft end of the flare at the 4 million per foot condition. The onset of smooth body transition is believed to be responsible for the increase and schlieren images (see Figure 17) confirm the bowshock flare-shock interaction is not responsible. The size of the separated flow region in front of the flare did not change significantly with Reynolds number and the boundary layer state on the flare transitioned at a lower Reynolds number as the angle of attack increased. Based on measured heating data at 8 and 16 degrees, it is speculated that the flow at 12 degrees transitions from laminar to transitional/turbulent beyond 4 million per foot.

\section{Concluding Remarks}

Aerodynamic and aeroheating data measured at Langley Research Center's 20-Inch Mach $6 \mathrm{CF}_{4}, 20$ Inch Mach $6 \mathrm{Air}$, and 31-Inch Mach 10 Air Tunnels on a one-percent scale model of Kistler Aerospace Corporation's baseline orbiter vehicle have been presented and compared with corresponding computational data predicted using the LAURA code. For aerodynamic coefficients and aeroheating levels, good agreement was observed between measured and computed values. This good agreement, which exists over a wide range in incidence ( -4 to 24 degrees), Mach number ( 6 to 10$)$, Reynolds number ( 0.5 to 4.0 million per foot), and ratio of specific heats (1.2 to 1.4), demonstrates the ability of the CFD tool to reproduce data at varied wind tunnel conditions and augments the credibility of LAURA to predict aerodynamic data and aeroheating data at flight conditions.

A non-linear behavior with incidence was observed in the measured aerodynamic data and was examined with CFD. It was determined from computational data 
that the flow over the flare was responsible for the nonlinear behavior; furthermore, the computational data showed that the contributions to aerodynamic coefficients derived from the flow over the nose and cylinder were linear versus incidence. At small angles of attack, the aerodynamic characteristics of the OV were primarily driven by pressure over the nose and cylinder. Near of 10 degrees angle of attack, the influence from the flare on aerodynamic characteristics was noticeable; beyond this angle, aerodynamic characteristics were primarily driven by pressure over the flare.

The influence of Mach number, Reynolds number, and ratio of specific heats on aerodynamic characteristics was also examined. Trim angle and trim $\mathrm{L} / \mathrm{D}$ increased slightly with increased Mach number. At Mach 6 in air, a Reynolds number effect was observed; trim angle and trim $L / D$ increased with Reynolds number. The ratio of specific heats had the greatest influence on aerodynamic values at trim. Upon comparing trim angle of attack and $\mathrm{L} / \mathrm{D}$ at trim in $\mathrm{CF}_{4}$ with perfect gas air values, a significant reduction in both was observed in $\mathrm{CF}_{4}$. Pressure levels over compression surfaces, like the OV flare, vary greatly with ratio of specific heats. The observed trends were a result of these pressure variances over the flare. If aerothermo-chemistry effects were not accounted for, a significant over prediction in trim angle and $\mathrm{L} / \mathrm{D}$ at trim would result. Because ideal and reacting gas flows have dissimilar pressure expansions/compressions and shock structures, all factors that can significantly influence aerodynamics, the influence of $\gamma$ must be accounted for when designing, screening, or evaluating any entry vehicle.

Measured aeroheating levels were inferred from the thermographic phosphor technique in air at Mach 6 . These aeroheating data were in the vicinity of the trim angle of attack and varied from 0.5 to 8.0 million per foot in Reynolds number. Along the entire windward centerline of the OV cylinder, the flow was laminar for all Reynolds numbers and angles considered. At 8 degrees, measured aeroheating data on the flare were independent of Reynolds number up to 4 million per foot, suggesting laminar flow. At 8 million per foot, the data were no longer independent of Reynolds number and the flow appeared transitional/turbulent. At 12 degrees, the measured heating data on the flare varied with Reynolds number and had a trend with Reynolds number that was not indicative of transitional/turbulent flow. However, measured heating levels were in the vicinity of those for laminar CFD predictions. At 16 degrees, the flow over the aft end flare is believed to be transitional/turbulent at 4 million per foot. When compared with data at lower Reynolds numbers, a rise in measured aeroheating values was observed at 4 million per foot condition.

\section{Acknowledgements}

The authors wish to acknowledge Christopher $\mathrm{J}$. Riley formerly of NASA Langley for providing the Mach 6 DPLUR inviscid predictions and Stephen J. Alter of NASA Langley for providing the surface and volume grids.

References
'Proctor, P., "Kistler Seeks to Create 'UPS of Space,' "
Aviation Week and Space Technology, June 30, 1997,
pp. 53-55 " Moorman, T., "The Explosion of Commercial Space Paper 98-0002, January 1998.

${ }^{3}$ Mueller, G. E., "A Low Cost Aerospace Vehicle." Acta Astronautica, Vol. 39, No. 1-4, 1996, pp. 239-244.

${ }^{4}$ Cheatwood, F. M. and Gnoffo, P. A., "User's Manual for the Largely Aerothermodynamic Upwind Relaxation Algorithm (LAURA)," NASA-TM4674, April 1996.

${ }^{5}$ Micol, J.R., "Langley Aerothermodynamic Facilities Complex: Enhancements and Testing Capabilities," AIAA Paper 98-0147, January 1998.

6 Micol, J. R., "Hypersonic Aerodynamic /Aerothermodynamic Testing Capabilities at Langley Research Center: Aerothermodynamic Facilities Complex," AIAA Paper 95-2107, June 1995.

7 Weilmuenster, K. J., Gnoffo, P. A., Greene, F. A.,"Navier-Stokes Simulations of Orbiter Aerodynamic Characteristics Including Pitch, Trim, and Bodyflap," Journal of Spacecraft and Rockets, Vol. 31, No. 3, May-June 1994, pp.355-366.

${ }^{8}$ Gnoffo, P. A., Weilmuenster, K. J., and Alter, S. J., "Multiblock Analysis for Shuttle Orbiter Re-Entry Heating From Mach 24 to Mach 12, Journal of Spacecraft and Rockets, Vol. 31, No. 3, May-June 1994, pp.367-377.

${ }^{9}$ Gnoffo, P. A., Braun, R. D., Weilmuenster, K. J., and Mitcheltree, R. A., "Prediction and Validation of Mars Pathfinder Hypersonic Aerodynamic Data Base," AIAA Paper 98-2459, June 1998.

${ }^{10}$ Hamilton, H. H., Greene, F. A., and Weilmuenster, K. J.,"Comparison of Heating Calculations with Experimental Data on a Modified Shuttle Orbiter,"Journal of Spacecraft and Rockets, Vol.29, No.2, March-April 1992, pp. 208-215.

11 Roe, P. L., "Approximate Riemann Solvers, Parameters Vectors, and Difference Schemes," Journal of Computational Physics, Vol. 43, No. 2, 1981, pp. 357-372.

12 Harten, A., "High Resolution Schemes for Hyperbolic Conservation Laws," Journal of Computational Physics, Vol. 49, No. 3, 1983, pp. 357393.

${ }^{13}$ Yee, H. C., "On Symmetric and Upwind TVD Schemes," NASA TM-86842, September 1985. 
14 Cheatwood, F. M. and Thompson, R. A., "The Addition of Algebraic Turbulence Models to Program LAURA," NASA TM-107758, April 1993.

15 Gnoffo, P. A., "An Upwind-Biased, Point-Implicit Relaxation Algorithm for Viscous Compressible Perfect-Gas Flows," NASA TP-2953, February 1990.

16 Greene, F. A., and Gupta, R. N., "Viscous Equilibrium Computations Using Program LARUA," Journal of Spacecraft and Rockets, Vol. 29, No. 5, 1992, pp. 627-632.

17 Gnoffo, P. A., Gupta, R. N., and Shinn, J. L., "Conservation Equations and Physical Models for Hypersonic Air Flows in Thermal and Chemical Nonequilibrium," NASA TP-2867, February 1989.

${ }^{18}$ Merski, R. N., "Global Aeroheating Wind-Tunnel Measurements Using Improved Two-Color Phosphor Thermography Method," Journal of Spacecraft and Rockets, Vol. 36, No. 2, April-May 1999, pp. 160-170.

19 Fitzgerald, P. E., "The Effect of Bow-Shock-FlareShock Interaction on the Static Longitudinal Stability of Flare-Stabilized Bodies," NASA TMX-664, March 1962.

${ }^{20}$ Kirk, D. B., "Free-Flight Investigation of the Static Stability of Blunt-Nosed Flare-Stabilized Entry Bodies at Mach Numbers from 5 to 16," NASA TMX-584, January 1962.

${ }^{21}$ Candler, G. V., Wright, M. J., and McDonald, J. D., "Data-Parallel Lower-Upper Relaxation Method for Reacting Flows," AIAA Journal, Vol. 32, No. 12, 1994, pp. 2380-2386.

${ }_{22}$ Menees, G. P. and Smith, W. G., "A Study of the Stability and Drag of Several Aerodynamic Shapes in Air, Carbon Dioxide, and Argon at Mach Numbers from 3 to 8," NASA TMX-950, February 1964.

${ }^{23}$ Midden, R. E., and Miller, C. G. III, "Description and Calibration of the Largely Hypersonic $\mathrm{CF}_{4}$ Tunnel - A Facility for Simulating Low $\gamma$ Flow as Occurs for a Real Gas," NASA TP-2384, March 1985.

${ }_{24}$ Weilmuenster, K. J., Gnoffo, P. A., and Greene, F. A., "Navier-Stokes Simulations of Orbiter Aerodynamic Characteristics Including Pitch Trim and Bodyflap, "Journal of Spacecraft and Rockets, Vol. 31, No. 3, May-June 1994, pp. 355-366.

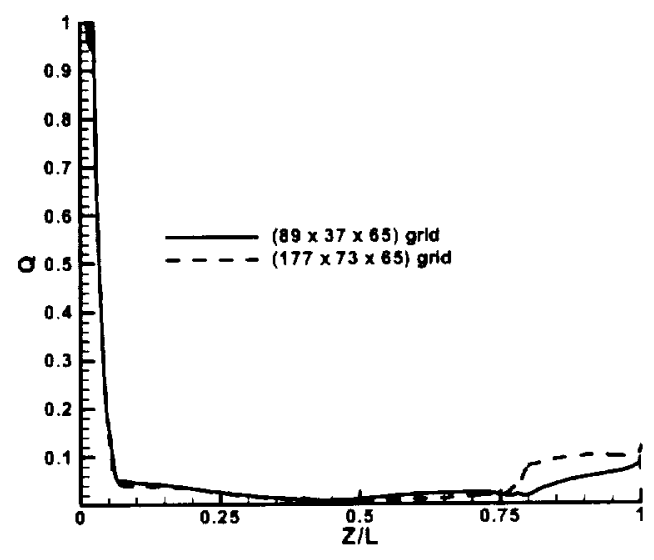

(a) Leeward symmetry plane $\left(\phi=0^{\circ}\right)$

Figure 4. Grid resolution on aeroheating levels, $\mathrm{M}_{\infty}=6, \operatorname{Re}=2 \times 10^{6} / \mathrm{ft}, \alpha=10^{\circ}$

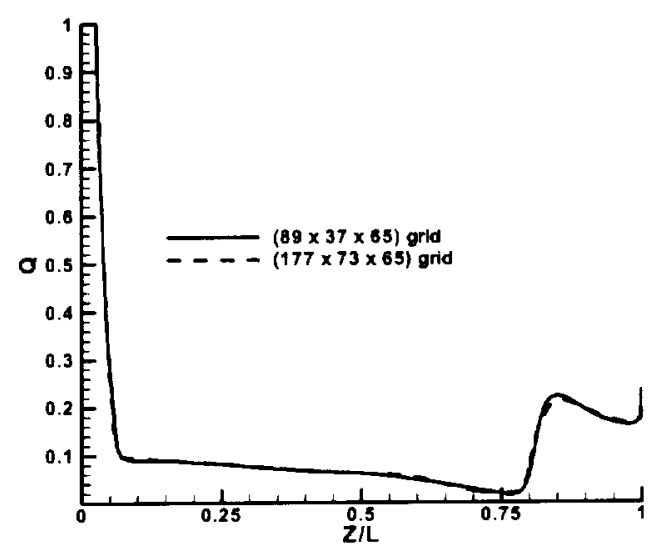

(b) Side plane $\left(\phi=90^{\circ}\right)$

Figure 4. Continued.

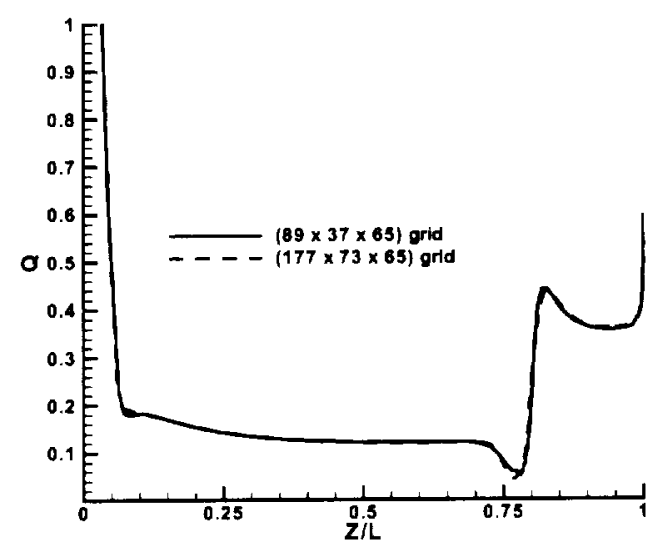

(c) Windward symmetry plane $\left(\phi=180^{\circ}\right)$ Figure 4. Concluded. 
Table 1. Nominal Tunnel Conditions.

\begin{tabular}{|c|c|c|c|c|c|c|c|c|}
\hline \multirow{2}{*}{ Facility } & \multirow{2}{*}{$\begin{array}{c}\text { Mach } \\
\text { No. }\end{array}$} & \multirow{2}{*}{$\begin{array}{l}\text { Reynolds } \\
\text { No. }[1 / \mathrm{ft}]\end{array}$} & \multirow{2}{*}{$T_{\infty}[R]$} & \multirow{2}{*}{$\mathbf{P}_{\infty}[\mathrm{psi}]$} & \multirow[b]{2}{*}{$\gamma_{\infty}$} & \multicolumn{3}{|c|}{ Angle of Attack } \\
\hline & & & & & & $\begin{array}{c}\text { Experiment } \\
\text { Aero } \\
\end{array}$ & $\begin{array}{c}\text { Experiment } \\
\text { Heating }\end{array}$ & CFD \\
\hline \multirow{4}{*}{$\begin{array}{c}\text { Mach } 6 \\
\text { Air }\end{array}$} & 5.83 & $0.5 \times 10^{6}$ & 111.4 & 0.022 & \multirow{4}{*}{1.40} & $-4 \rightarrow 24,4$ & - ----- & $0,10,15,20$ \\
\hline & 5.88 & $1.0 \times 10^{6}$ & 112.4 & 0.044 & & $-4 \rightarrow 24,4$ & $8,12,16$ & -...--- \\
\hline & 5.93 & $2.0 \times 10^{6}$ & 113.7 & 0.085 & & $-4 \rightarrow 24,4$ & $8,12,16$ & $0,10,15$ \\
\hline & 5.98 & $4.0 \times 10^{6}$ & 111.8 & 0.161 & & $-4 \rightarrow 16,4$ & $8,12,16$ & $0,4,10,15$ \\
\hline $\begin{array}{c}\text { Mach } 6 \\
\mathrm{CF}_{4}\end{array}$ & 6.18 & $0.4 \times 10^{6}$ & 324.2 & 0.054 & 1.22 & $-4 \rightarrow 24,4$ & ------ & $0,10,20,24$ \\
\hline \multirow{3}{*}{$\begin{array}{l}\text { Mach } 10 \\
\text { Air }\end{array}$} & 9.84 & $0.5 \times 10^{6}$ & 93.6 & 0.009 & \multirow{3}{*}{1.40} & $-4 \rightarrow 24,4$ & ----י-- & $0,4,10,15$ \\
\hline & 9.84 & $1.1 \times 10^{6}$ & 93.6 & 0.018 & & $-4 \rightarrow 24,4$ & -.---- & ------- \\
\hline & 9.83 & $2.2 \times 10^{6}$ & 93.6 & 0.032 & & $-4 \rightarrow 24,4$ & $8,12,16$ & $0,4,10,15$ \\
\hline
\end{tabular}

Table 2. Estimated Aerodynamic Uncertainties.

\begin{tabular}{|c|c|c|c|c|}
\hline \multirow{2}{*}{ Facility } & $\begin{array}{c}\text { Reynolds No. } \\
{[\mathbf{1} / \mathbf{f t}]}\end{array}$ & $\mathbf{C}_{\mathbf{A}}$ & $\mathbf{C}_{\mathbf{x}}$ & $\mathbf{C}_{\mathbf{m}}$ \\
\hline \multirow{3}{*}{ Mach 6 Air } & $0.5 \times 10^{6}$ & 0.069 & 0.034 & 0.023 \\
\cline { 2 - 5 } & $1.0 \times 10^{6}$ & 0.033 & 0.016 & 0.011 \\
\cline { 2 - 5 } & $2.0 \times 10^{6}$ & 0.017 & 0.008 & 0.006 \\
\cline { 2 - 5 } & $4.0 \times 10^{6}$ & 0.008 & 0.004 & 0.003 \\
\hline Mach 6 CF 4 & $0.4 \times 10^{6}$ & 0.036 & 0.018 & 0.012 \\
\hline \multirow{2}{*}{ Mach 10 Air } & $0.5 \times 10^{6}$ & 0.054 & 0.027 & 0.018 \\
\cline { 2 - 5 } & $1.1 \times 10^{6}$ & 0.026 & 0.013 & 0.009 \\
\cline { 2 - 5 } & $2.2 \times 10^{6}$ & 0.014 & 0.007 & 0.005 \\
\hline
\end{tabular}

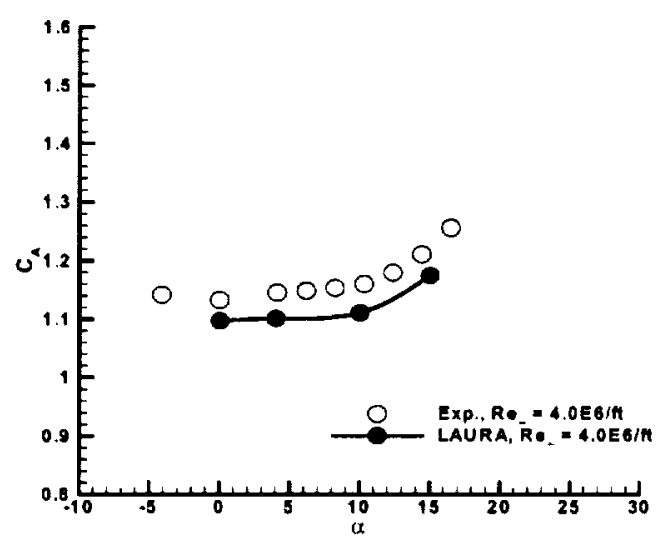

(a) Axial force coefficient

Figure 5. Predicted vs. measured aerodynamics for OV in air at $\mathrm{M}_{\infty}=6$.

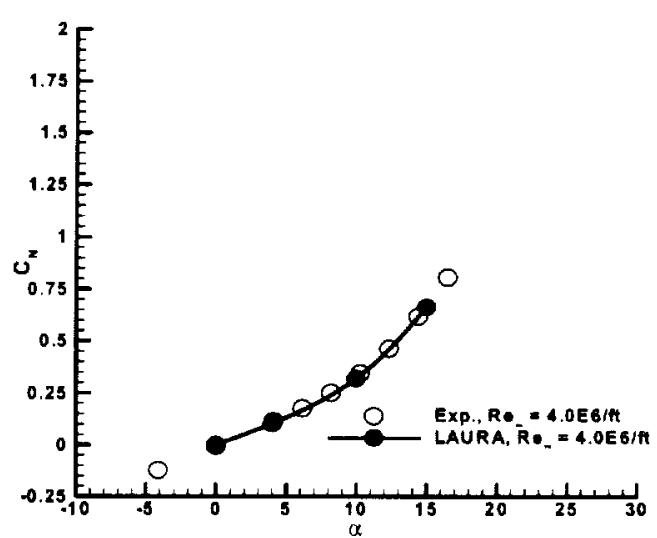

(b) Normal force coefficient Figure 5. Continued. 


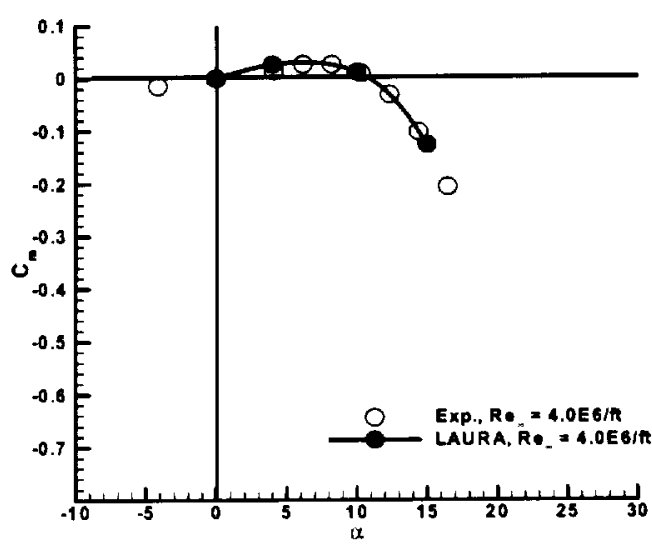

(c) Pitching moment coefficient Figure 5. Continued.

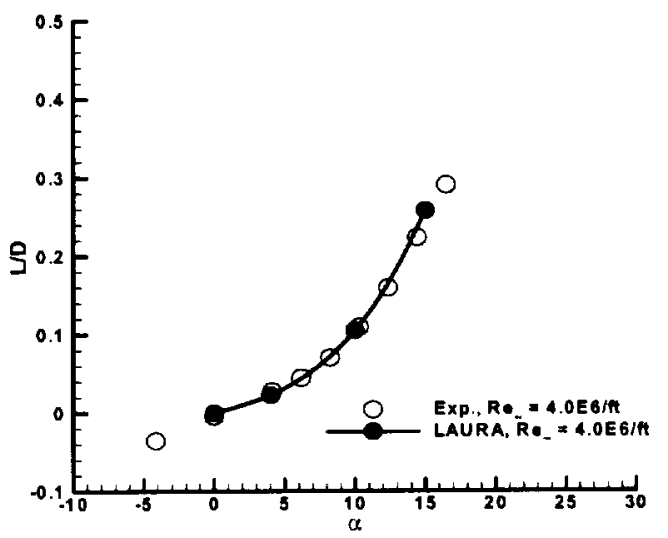

(d) Lift-to-drag ratio Figure 5. Concluded.

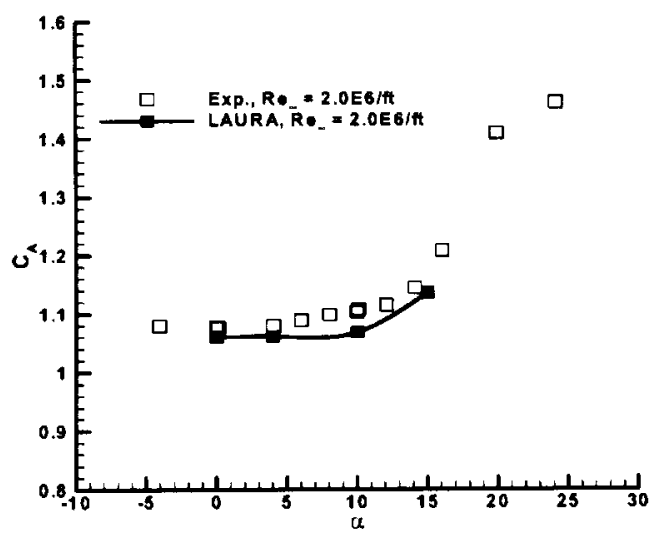

(a) Axial force coefficient

Figure 6. Predicted vs. measured aerodynamics for $\mathrm{OV}$ in air at $\mathrm{M}_{\infty}=10$.

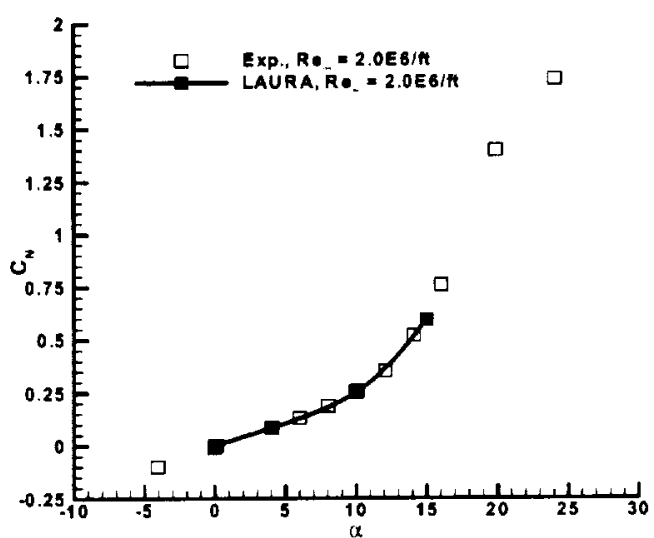

(b) Normal force coefficient Figure 6. Continued.

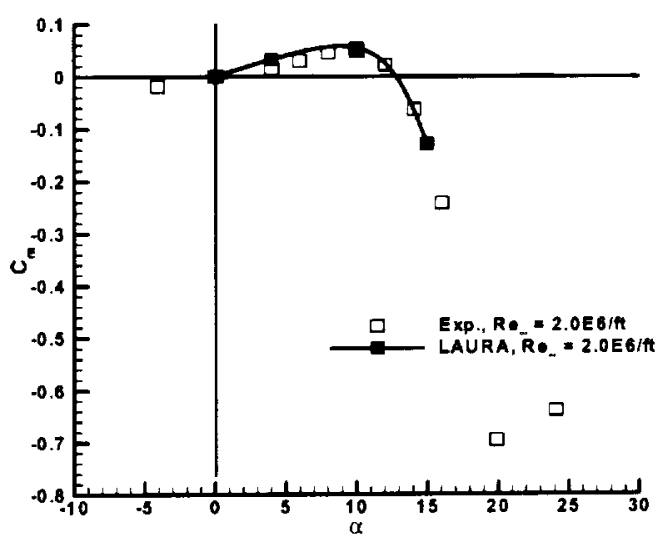

(c) Pitching moment coefficient Figure 6. Continued.

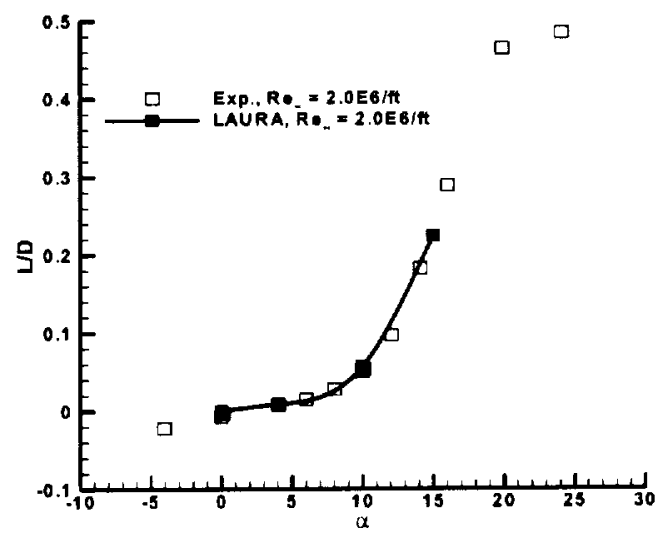

(d) Lift-to-drag ratio Figure 6. Concluded. 


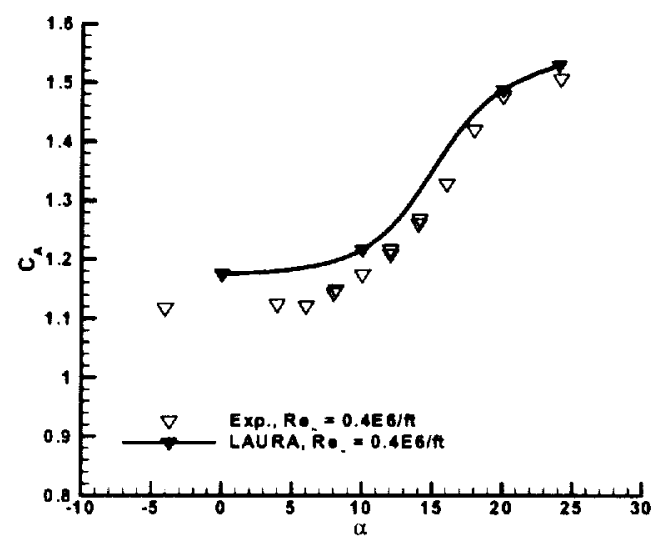

(a) Axial force coefficient

Figure 7. Predicted vs. measured aerodynamics for $\mathrm{OV}$ in $\mathrm{CF}_{4}$ at $\mathrm{M}_{\infty}=6$.

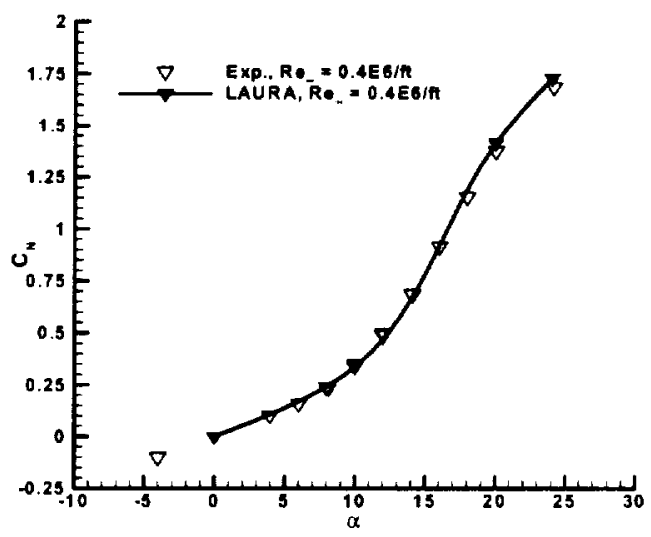

(b) Normal force coefficient Figure 7. Continued.

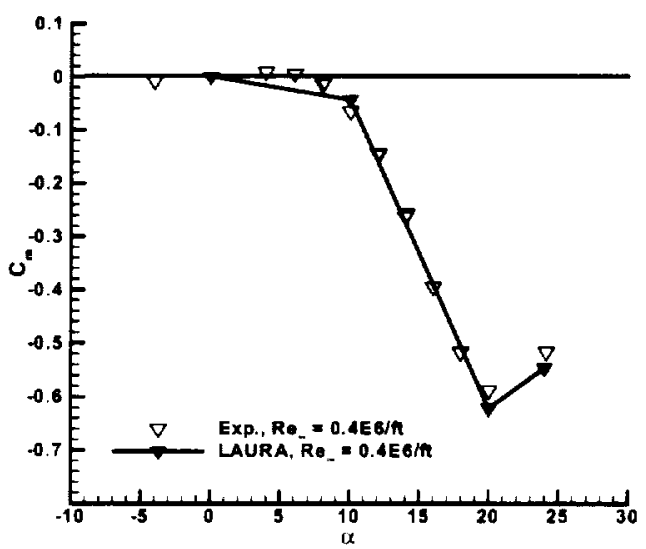

(c) Pitching moment coefficient Figure 7. Continued.

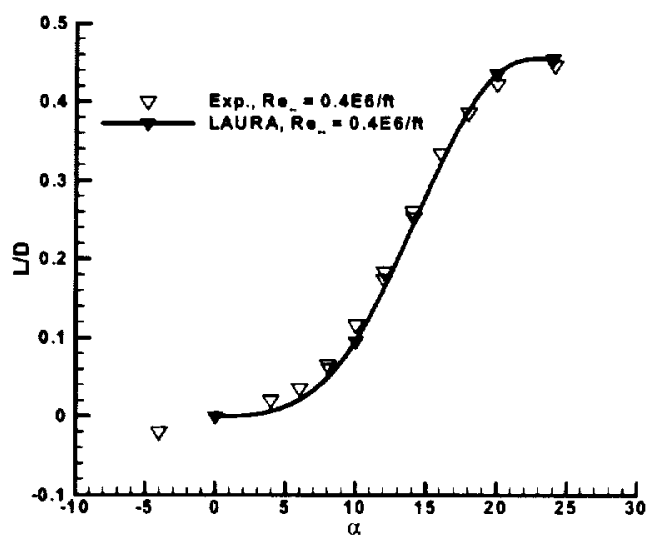

(d) Lift-to-drag ratio Figure 7. Concluded.

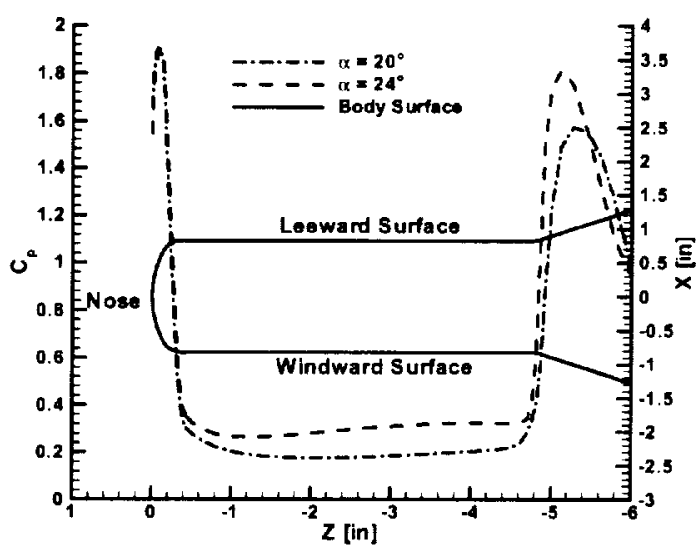

Figure 8. Pressure coefficient on the $\mathrm{OV}$ windward centerline in $\mathrm{CF}_{4}$ at $\mathrm{M}_{\infty}=6, \operatorname{Re}=0.4 \times 10^{6} / \mathrm{ft}$.

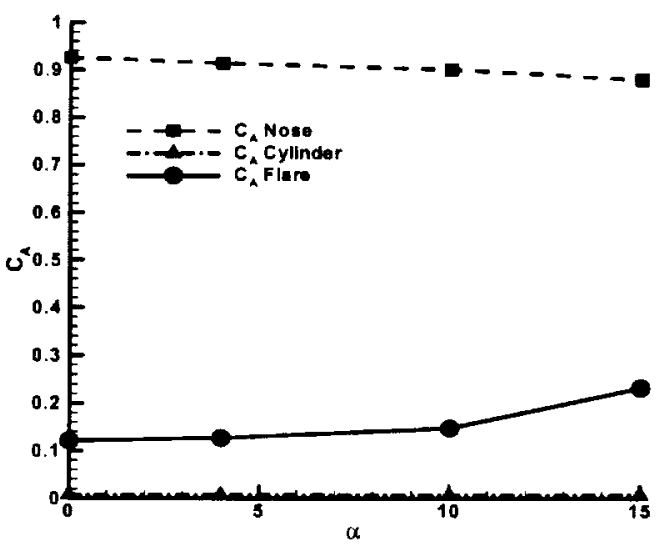

(a) Axial force coefficient

Figure 9. Aerodynamic contributions from nose, cylinder, and flare in air at $\mathrm{M}_{\infty}=6, \mathrm{Re}=4.0 \times 10^{6} / \mathrm{ft}$. 


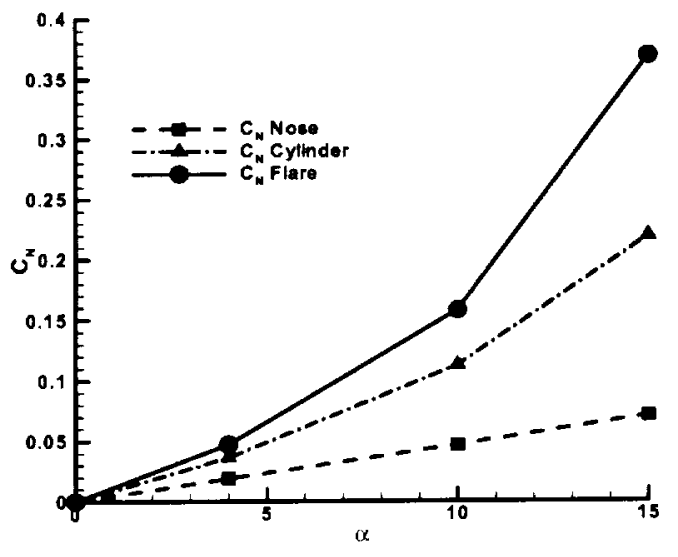

(b) Normal force coefficient

Figure 9. Continued.

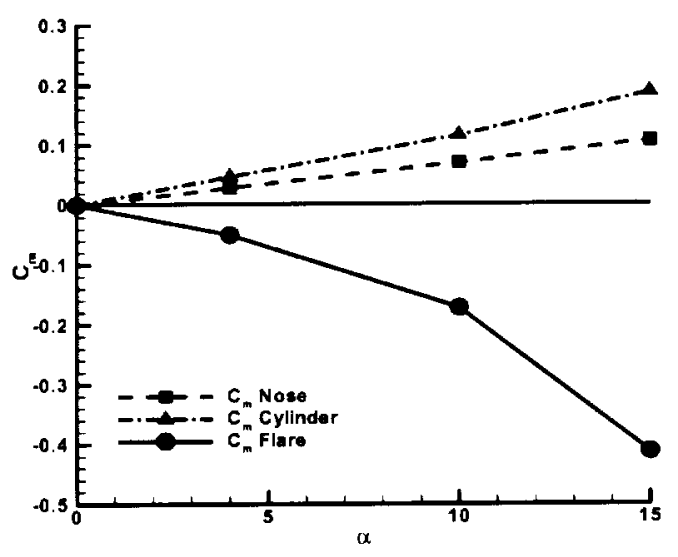

(c) Pitching moment coefficient Figure 9. Concluded.

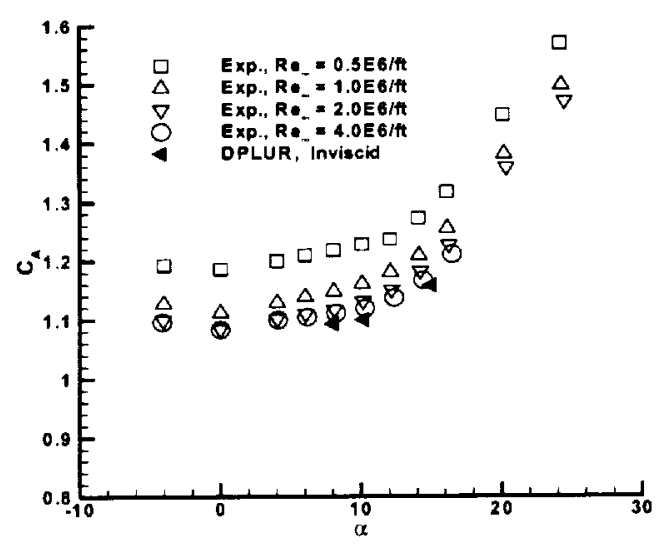

(a) Axial force coefficient

Figure 10. Effects of Reynolds number on OV aerodynamics in air at $M_{\infty}=6$.

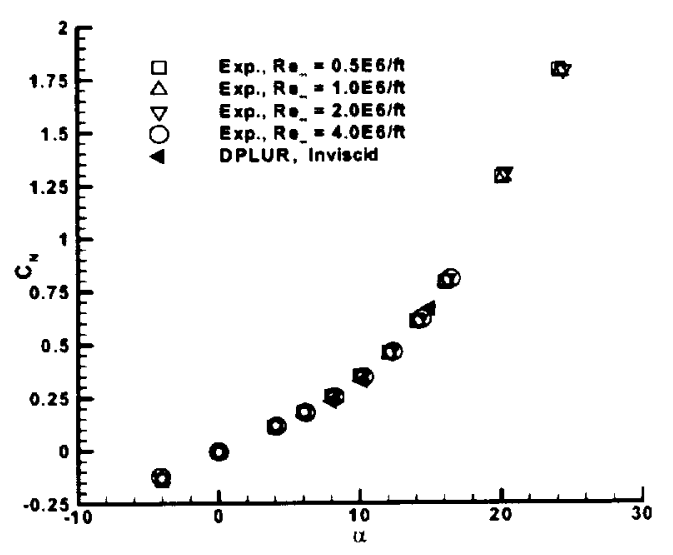

(b) Normal force coefficient Figure 10. Continued.

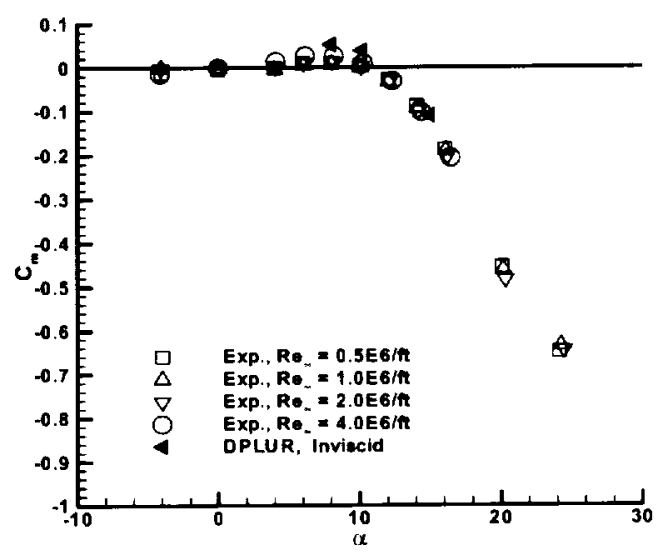

(c) Pitching moment coefficient Figure 10. Continued.

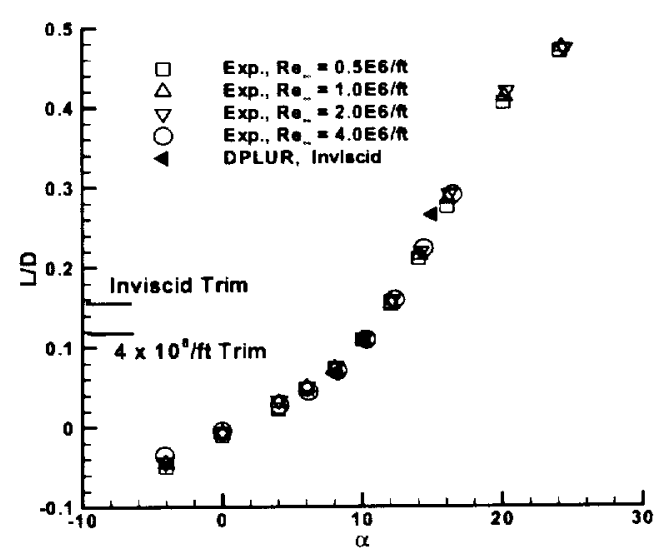

(d) Lift-to-drag ratio Figure 10. Concluded. 


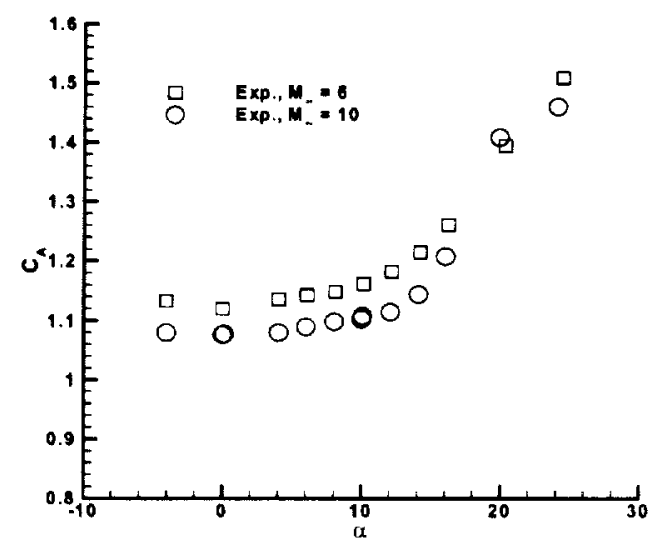

(a) Axial force coefficient

Figure 11. Effects of Mach number on OV aerodynamics in air, $\operatorname{Re}=2.0 \times 10^{6} / \mathrm{ft}$.

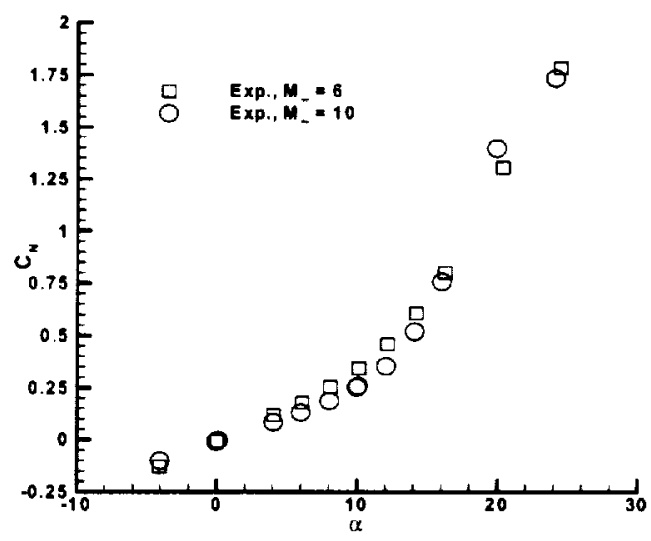

(b) Normal force coefficient Figure 11. Continued.

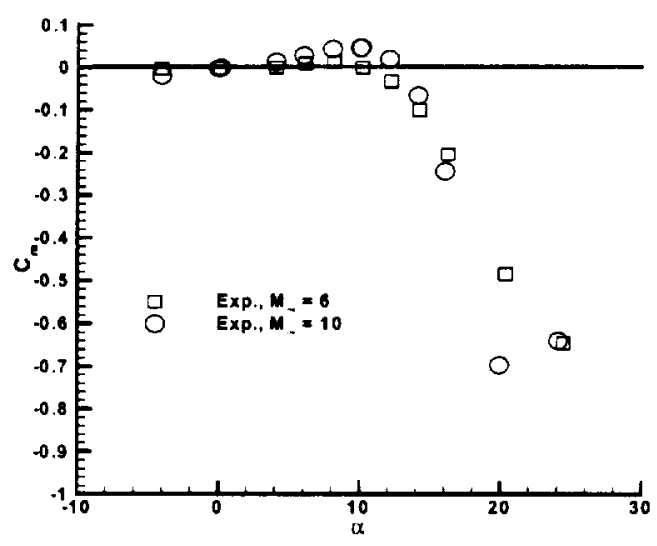

(c) Pitching moment coefficient Figure 11. Continued.

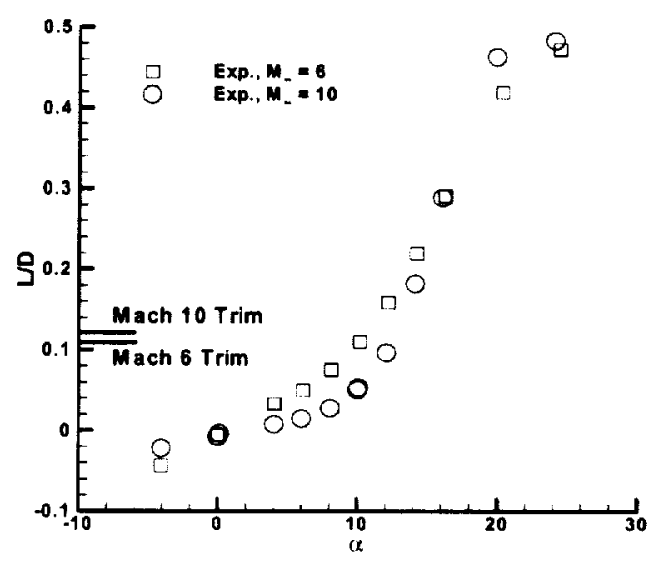

(d) Lift-to-drag ratio

Figure 11. Concluded.

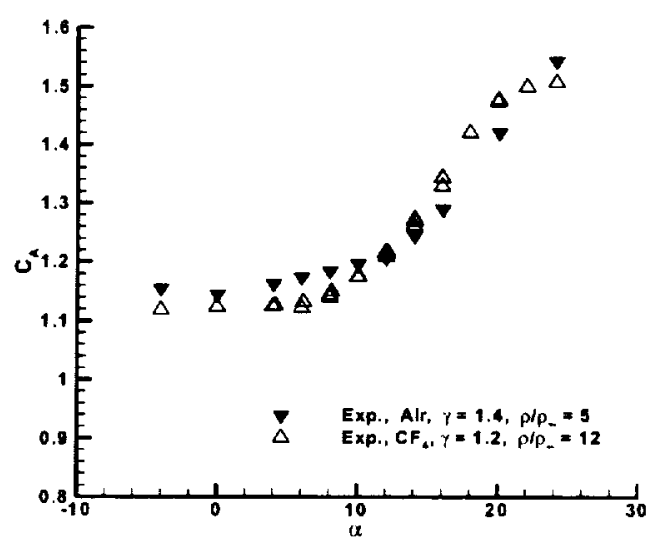

(a) Axial force coefficient

Figure 12. Effects of $\gamma$ on $\mathrm{OV}$ aerodynamics at $\mathrm{M}_{\infty}=6$, $\operatorname{Re} \approx 0.5 \times 10^{6} / \mathrm{ft}$.

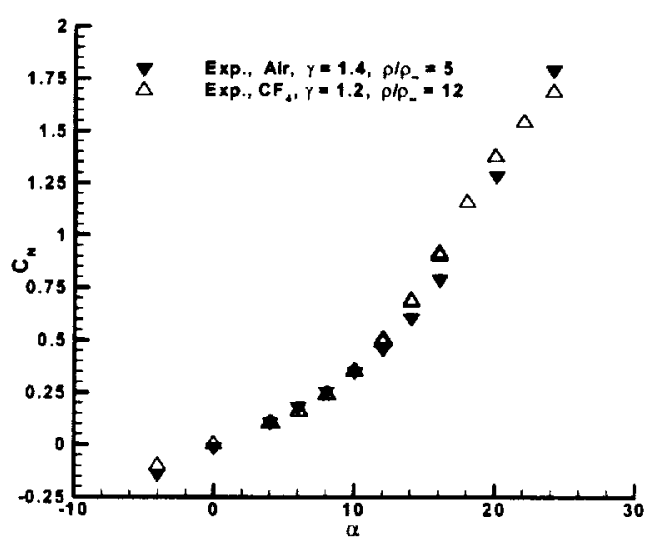

(b) Normal force coefficient Figure 12. Continued. 


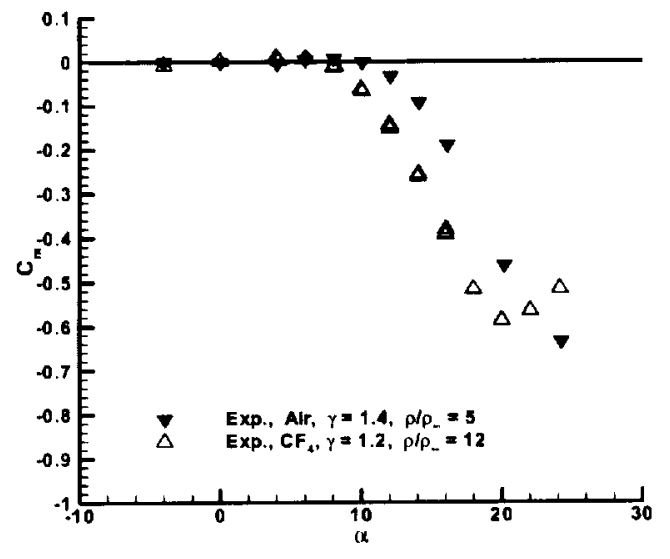

(c) Pitching moment coefficient Figure 12. Continued.

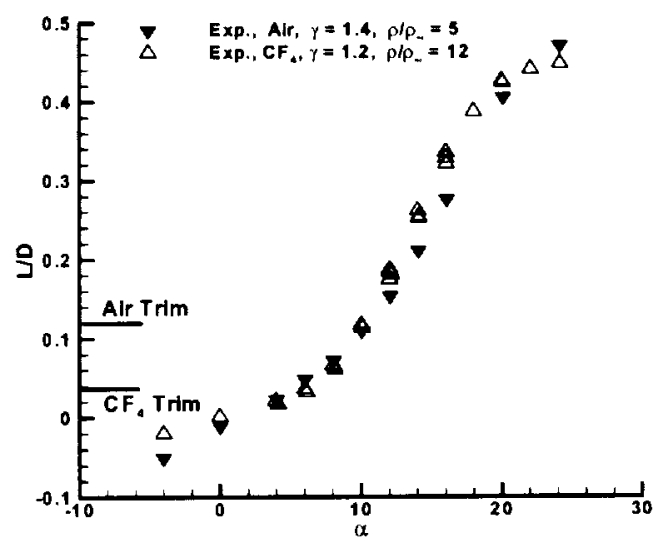

(d) Lift-to-drag ratio

Figure 12. Concluded.

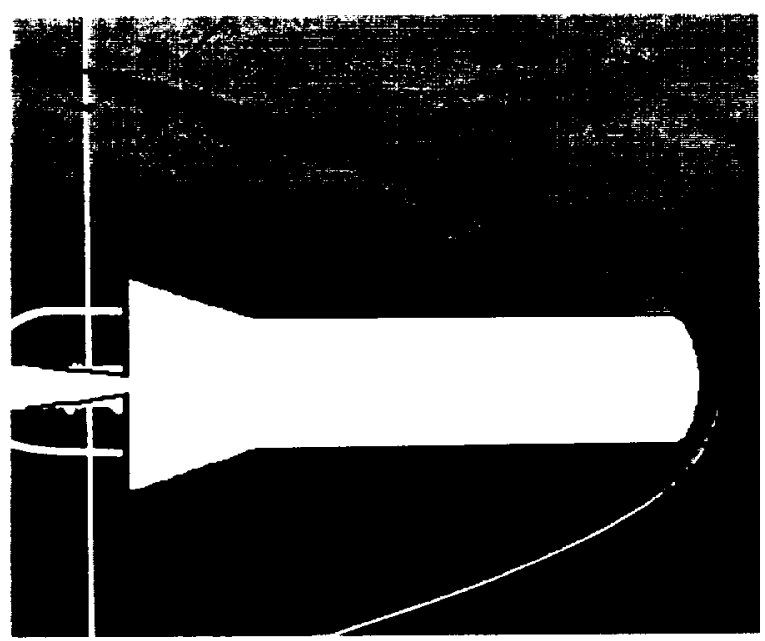

(a) $\alpha=0.0$ degrees

Figure 13. Measured schlieren images at Mach 6 in air compared with computed shock shapes for air and $\mathrm{CF}_{4}$.

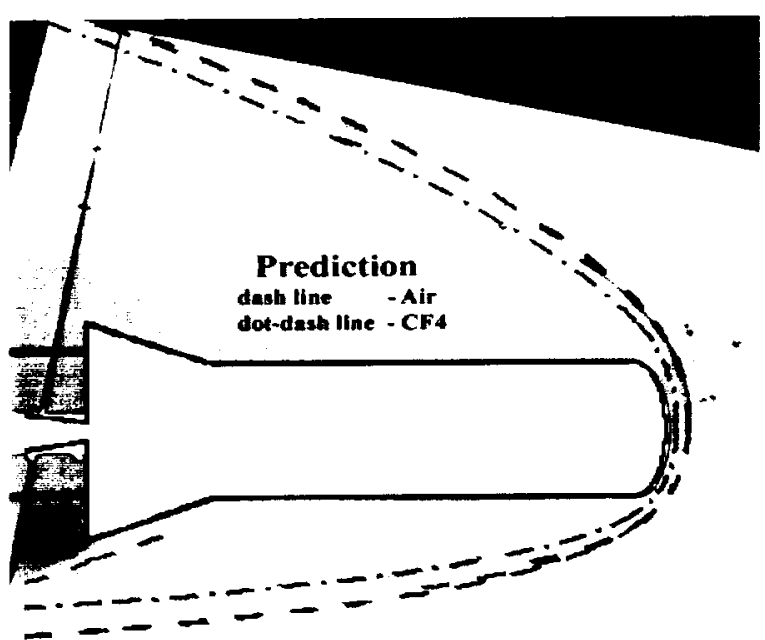

(b) $\alpha=10.0$ degrees

Figure 13. Continued.

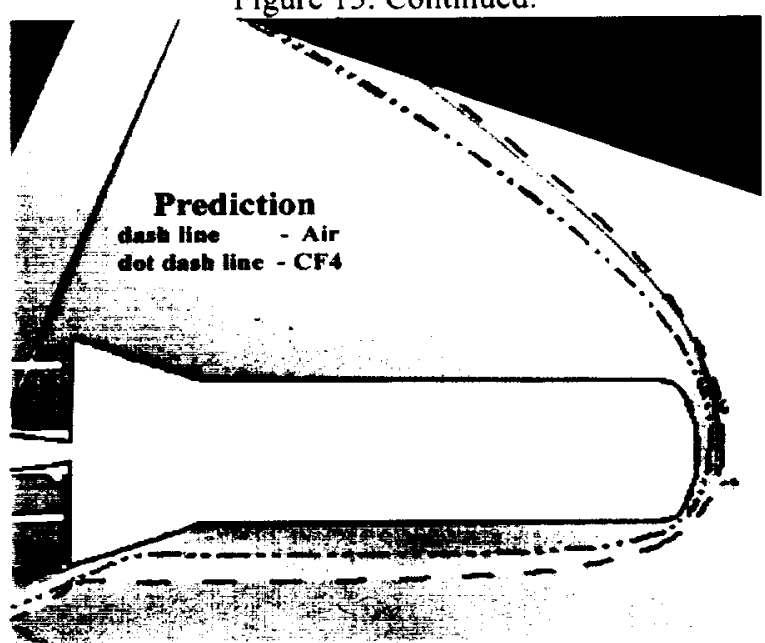

(c) $\alpha=20.0$ degrees

Figure 13. Concluded.

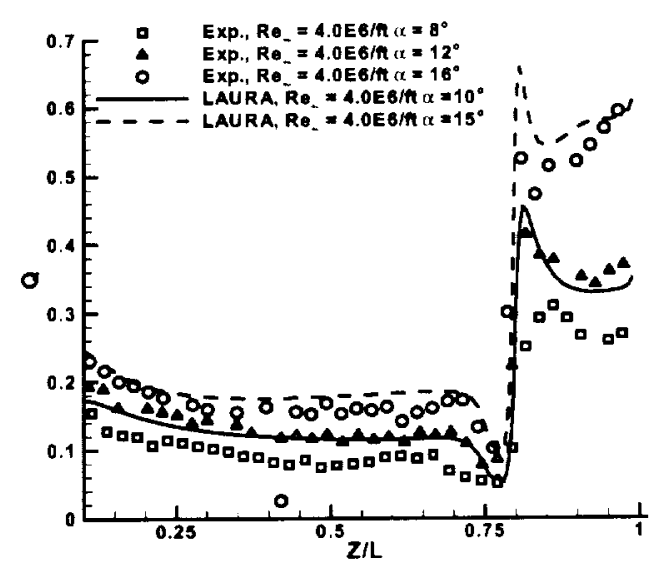

(a) $M_{\infty}=6(\phi=180)$

Figure 14. Measured vs. predicted surface heating values along the $O V$ windward centerline in air. 


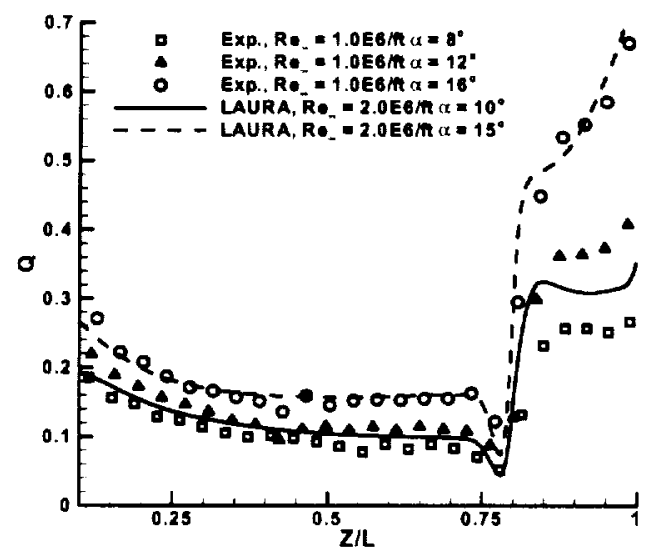

(b) $M_{\infty}=10(\phi=180)$

Figure 14. Concluded.

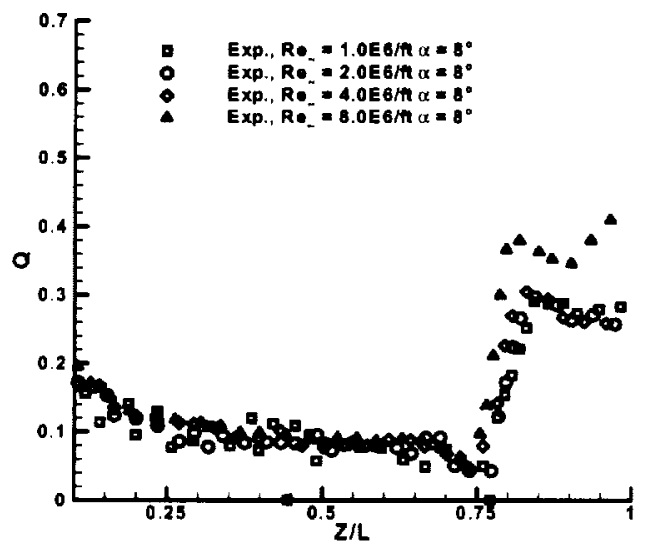

(a) Windward centerline, $\alpha=8^{\circ}$

Figure 15. Effects of Reynolds number at $\mathrm{M}_{\infty}=6$.

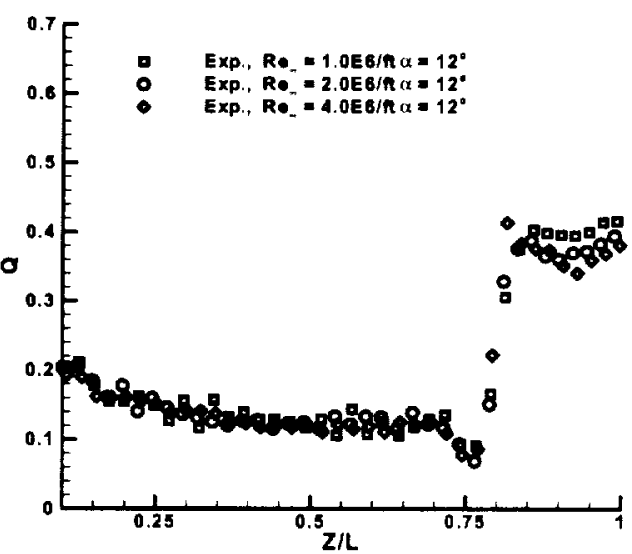

(b) Windward centerline, $\alpha=12^{\circ}$ Figure 15. Continued.

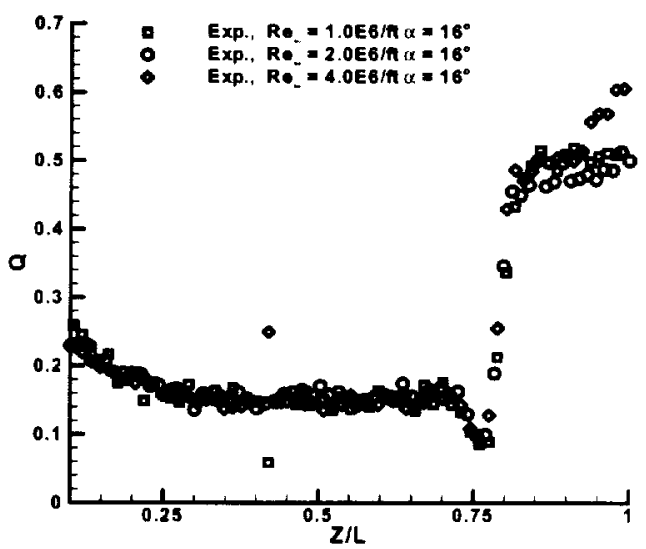

(c) Windward centerline, $\alpha=16^{\circ}$ Figure 15. Concluded.

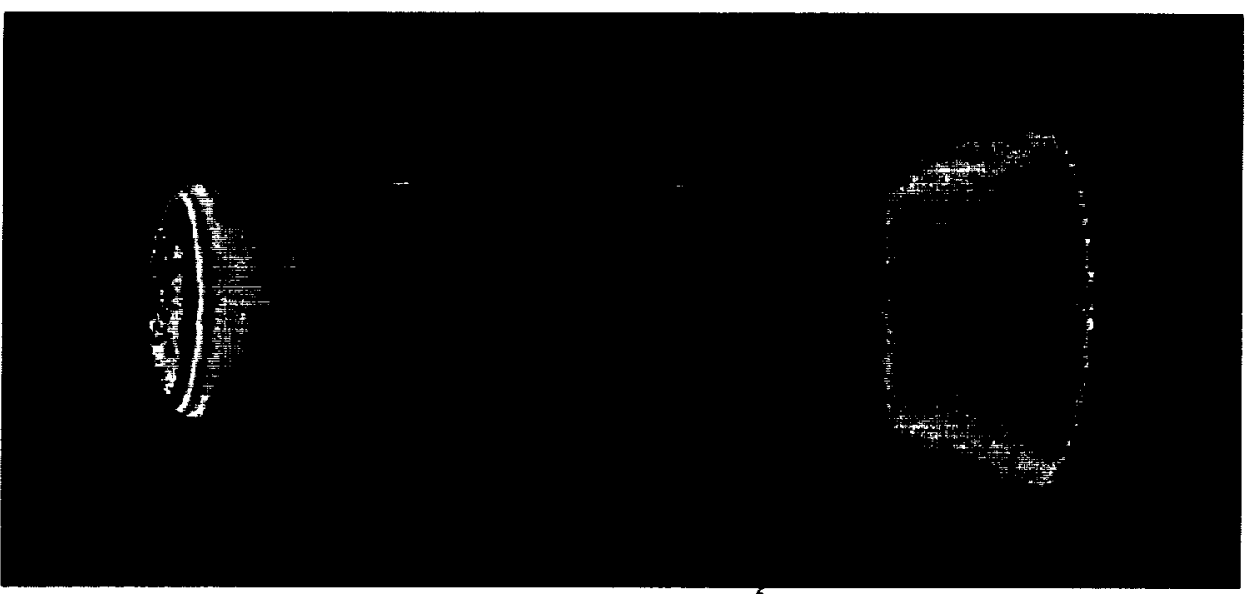

(a) $\operatorname{Re}=1.0 \times 10^{6} / \mathrm{ft}$

Figure 16. Effect of Reynolds number on windward heating, $\mathrm{M}_{\infty}=6$ air, $\alpha=16^{\circ}$. 


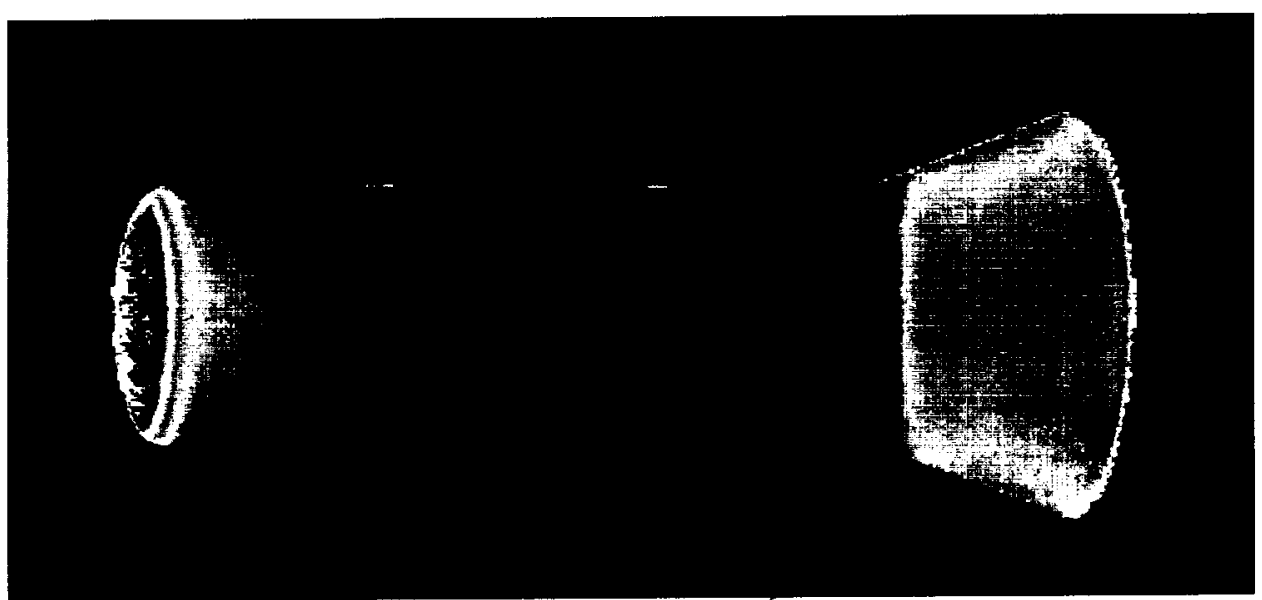

(b) $\operatorname{Re}=2.0 \times 10^{6} / \mathrm{ft}$

Figure 16. Continued.

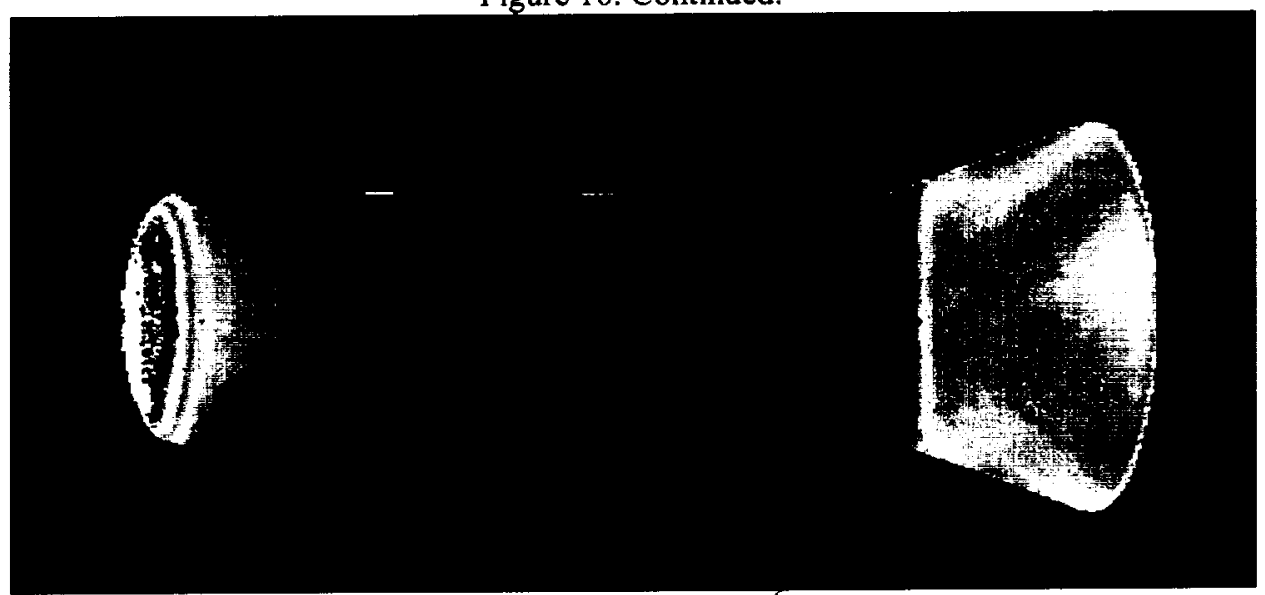

(c) $\operatorname{Re}=4.0 \times 10^{6} / \mathrm{ft}$

Figure 16. Concluded.

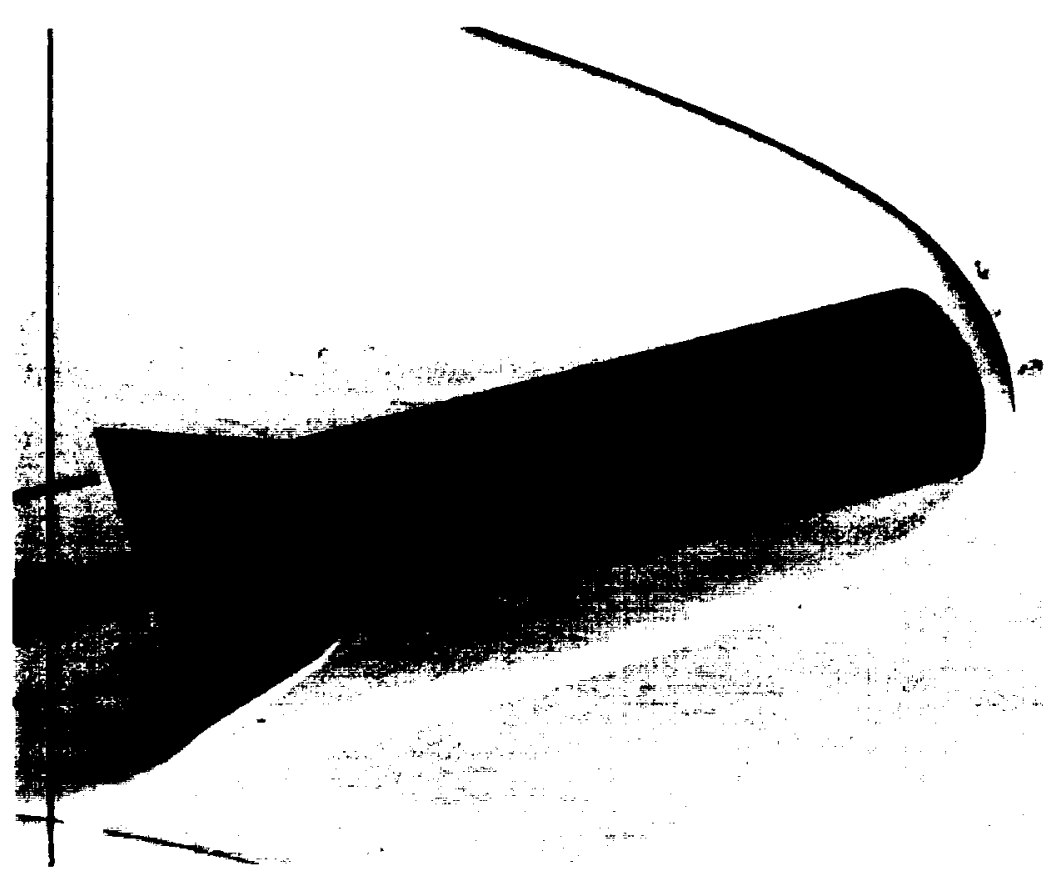

Figure 17. Measured schlieren image at Mach 6 in air, $\alpha=16$ degrees. 


\author{
-
}



